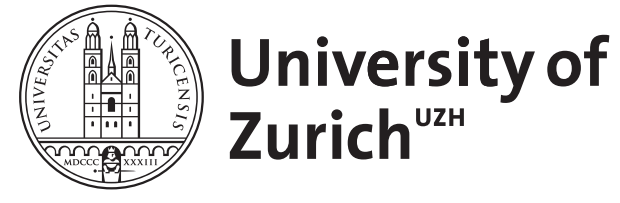

\title{
The evolution of general intelligence
}

\author{
Burkart, Judith M ; Schubiger, Michèle N ; van Schaik, Carel P
}

\begin{abstract}
The presence of general intelligence poses a major evolutionary puzzle, which has led to increased interest in its presence in nonhuman animals. The aim of this review is to critically evaluate this puzzle, and to explore the implications for current theories about the evolution of cognition. We first review domain-general and domain-specific accounts of human cognition in order to situate attempts to identify general intelligence in nonhuman animals. Recent studies are consistent with the presence of general intelligence in mammals (rodents and primates). However, the interpretation of a psychometric g-factor as general intelligence needs to be validated, in particular in primates, and we propose a range of such tests. We then evaluate the implications of general intelligence in nonhuman animals for current theories about its evolution and find support for the cultural intelligence approach, which stresses the critical importance of social inputs during the ontogenetic construction of survival-relevant skills. The presence of general intelligence in nonhumans implies that modular abilities can arise in two ways, primarily through automatic development with fixed content and secondarily through learning and automatization with more variable content. The currently best-supported model, for humans and nonhuman vertebrates alike, thus construes the mind as a mix of skills based on primary and secondary modules. The relative importance of these two components is expected to vary widely among species, and we formulate tests to quantify their strength.
\end{abstract}

DOI: https://doi.org/10.1017/S0140525X16000959

Posted at the Zurich Open Repository and Archive, University of Zurich

ZORA URL: https://doi.org/10.5167/uzh-125477

Journal Article

Accepted Version

Originally published at:

Burkart, Judith M; Schubiger, Michèle N; van Schaik, Carel P (2017). The evolution of general intelligence. Behavioral and Brain Sciences, 40:e195.

DOI: https://doi.org/10.1017/S0140525X16000959 
To be published in Behavioral and Brain Sciences (in press)

C Cambridge University Press 2016

Below is an unedited, uncorrected BBS Target Article recently accepted for publication. This preprint has been prepared specifically for potential commentators who wish to nominate themselves for formal commentary invitation via Editorial Manager: http://bbs.edmgr.com/. The Commentary Proposal Instructions can be accessed here: http://journals.cambridge.org/action/displaySpecialPage?pageId=5544

Please DO NOT write a commentary unless you receive a formal email invitation from the Editors. If you are invited to submit a commentary, a copyedited, corrected version of this paper will be made available.

\title{
The evolution of general intelligence
}

Judith M. Burkart, Michèle N. Schubiger, Carel P. van Schaik

Anthropological Institute and Museum, Winterthurerstrasse 190, CH-8057 Zurich

Corresponding author: Judith.Burkart@aim.uzh.ch

\begin{abstract}
The presence of general intelligence poses a major evolutionary puzzle, which has led to increased interest in its presence in nonhuman animals. The aim of this review is to critically evaluate this puzzle, and to explore the implications for current theories about the evolution of cognition. We first review domain-general and domain-specific accounts of human cognition in order to situate attempts to identify general intelligence in nonhuman animals. Recent studies are consistent with the presence of general intelligence in mammals (rodents and primates). However, the interpretation of a psychometric g-factor as general intelligence needs to be validated, in particular in primates, and we propose a range of such tests. We then evaluate the implications of general intelligence in nonhuman animals for current theories about its evolution and find support for the cultural intelligence approach, which stresses the critical importance of social inputs during the ontogenetic construction of survival-relevant skills. The presence of general intelligence in nonhumans implies that modular abilities can arise in two ways, primarily through automatic development with fixed content and secondarily through learning and automatization with more variable content. The currently best-supported model, for humans and nonhuman vertebrates alike, thus construes the mind as a mix of skills based on primary and secondary modules. The relative importance of these two components is expected to vary widely among species, and we formulate tests to quantify their strength.
\end{abstract}


Keywords: general intelligence, psychometric intelligence, evolution of intelligence, positive manifold, modularity, social learning, cultural intelligence, nonhuman primates, rodents, species comparisons, comparative approach, brain size evolution 


\section{The evolution of general intelligence}

Judith M. Burkart, Michèle N. Schubiger, Carel P. van Schaik

Anthropological Institute and Museum, Winterthurerstrasse 190, CH-8057 Zurich

Corresponding author: Judith.Burkart@aim.uzh.ch

Word counts:

- Long abstract: 229

- Short abstract: 99

- Main text (without references, Figures and Tables):15541

- References: 5925

\section{Contents}

1. Domain-general and domain-specific accounts of human cognition

1.1 The positive manifold and general intelligence

1.1.1 The structure of cognition

1.1.2 Executive functions and intelligence

1.2 Cognitive adaptations and domain specificity

1.2.1 Modularity and intelligence

1.2.2 Adaptive canalization beyond modularity

1.2.3 Primary and secondary modularization, and implications for general intelligence in animals

\section{General intelligence in nonhuman animals?}

2.1 Intra-specific studies of psychometric intelligence: $g$

2.2 Inter-specific studies of psychometric intelligence: $G$

2.3 Mixed studies combining intra- and inter-specific variation

2.4 Facts or artifacts?

2.4.1 Statistical issues

2.4.2 Methodological issues

2.4.3 False negatives as a result of secondary modularization

2.5 Psychometric or general intelligence? Future directions for animal studies

\section{Implications for the evolution of general intelligence}

3.1 General intelligence as response to domain-specific pressures

3.2 Direct selection on general intelligence

3.3 Who can afford general intelligence? Cultural intelligence

\section{Discussion}

4.1 Preliminary synthesis

4.2 Conclusions 


\section{Long abstract}

The presence of general intelligence poses a major evolutionary puzzle, which has led to increased interest in its presence in nonhuman animals. The aim of this review is to critically evaluate this puzzle, and to explore the implications for current theories about the evolution of cognition. We first review domain-general and domain-specific accounts of human cognition in order to situate attempts to identify general intelligence in nonhuman animals. Recent studies are consistent with the presence of general intelligence in mammals (rodents and primates). However, the interpretation of a psychometric $g$-factor as general intelligence needs to be validated, in particular in primates, and we propose a range of such tests. We then evaluate the implications of general intelligence in nonhuman animals for current theories about its evolution and find support for the cultural intelligence approach, which stresses the critical importance of social inputs during the ontogenetic construction of survival-relevant skills. The presence of general intelligence in nonhumans implies that modular abilities can arise in two ways, primarily through automatic development with fixed content and secondarily through learning and automatization with more variable content. The currently best-supported model, for humans and nonhuman vertebrates alike, thus construes the mind as a mix of skills based on primary and secondary modules. The relative importance of these two components is expected to vary widely among species, and we formulate tests to quantify their strength.

\section{Short Abstract}

We critically evaluate increasing evidence for general intelligence in nonhuman animals in light of the large body of knowledge accumulated on human cognition. Current evidence is consistent with the presence of general intelligence in nonhumans, but we stress the need to complement the interpretation of a psychometric $g$-factor as general intelligence with additional validation tests and formulate future directions for comparative approaches. We evaluate the implications for current theories about the evolution of intelligence and propose that the cultural intelligence approach, which stresses the critical importance of social inputs during the ontogenetic construction of survival-relevant skills, is best supported.

Key words: general intelligence, psychometric intelligence, evolution of intelligence, positive manifold, modularity, social learning, cultural intelligence, nonhuman primates, rodents, species comparisons, comparative approach, brain size evolution 


\section{Domain-general and domain-specific accounts of human cognition}

"Animal behavior is driven by instincts, whereas human beings behave rationally." Views like these are still commonly expressed and deeply anchored in the Western worldview (e.g. Pinker 2010). A modern version of this dichotomy construes animals as having domain-specific, modular cognitive adaptations, whereas humans have domain-general intelligence. However, we now know that in human cognition, domain-specific components are ubiquitous too (Cosmides \& Tooby 2013), perhaps even in complex cognitive tasks such as logical inference (Cosmides, Barrett \& Tooby 2010) or solving Bayesian probability problems (Lesage, Navarrete \& De Neys 2013). At the same time, much evidence has accumulated that nonhuman minds are not exclusively made up of domain-specific specializations, but that domain-general cognitive processes may also be widespread. These empirical findings have implications for contemporary theories of the evolution of general intelligence, highlighted in section three, provided it is established that general intelligence in animals is both real and refers to the same construct as in humans.

The evolution of general intelligence poses a major puzzle. Because modular systems may readily evolve (Pavlicev \& Wagner 2012; Schlosser \& Wagner 2004; Shettleworth 2012; but see Anderson \& Finlay 2014; Lefebvre 2014), the evolution of the mind as a set of domain-specific adaptations or modules can easily be imagined. Indeed, a small set of dedicated modules, without any domain-general cognitive abilities, to which additional modules can be added as needed, may be the ancestral state of vertebrate cognition. This perspective is so convincing that it has led to accounts of massive modularity, not only for animal cognition, but for human cognition as well (reviews: Barrett 2015; Frankenhuis \& Ploeger 2007; Hufendiek \& Wild 2015).

Evolutionary pathways leading to the emergence of domain-general cognitive processes, on the other hand, may appear less straightforward, because such open-content processes translate far less reliably into fitness-enhancing behavior, and because they may also require disproportionate amounts of energetically costly brain tissue compared to domain-specific specializations (van Schaik, Isler \& Burkart 2012). Consequently, compared to the evolution of additional cheap and reliable, domain-specific, specialized cognitive solutions to specific problems, the evolution of general cognitive processes might pose greater obstacles to natural selection. Nonetheless, humans possess general intelligence, and if general intelligence can also be found in nonhuman animals, we can attempt to identify the evolutionary processes that can lead to its emergence, including the specific case of humans.

The aims of this review are (i) to critically evaluate the evidence for general intelligence in nonhuman animals, and (ii) to explore the implications of its presence in nonhumans for current theories of cognitive evolution. To achieve these aims, we will review the theoretical background and evidence 
from a variety of research traditions, such as animal behavior and psychology, psychometrics and developmental psychology, and evolutionary psychology. Whereas all these fields share an interest in understanding how the mind works, they are not well integrated and attempts at integration have not yet to produce consensus (e.g., Eraña 2012; Evans 2011, 2013; Toates 2005). In the present paper, we will therefore selectively focus on those aspects that are necessary to integrate the findings from animal studies on general intelligence with what is known about humans. As non-experts in several of these fields, we are aware that we may not fully represent all the relevant aspects of the respective theories, let alone solve current controversies in individual fields. Nevertheless, we hope that this paper serves as a first step in achieving the much-needed integration across these disciplines at a more fine-grained level, which will eventually enable the development of a more unified theory of cognitive evolution.

This paper is structured as follows. We will first briefly review conceptualizations of both domain-generality and domain-specificity of human cognition, and use this as background to situate current evidence for general intelligence in nonhuman animals, which is increasingly reported in various species based on factor-analytical approaches. We will examine alternative explanations for these findings and develop a set of empirical criteria to investigate to what extent a statistically derived psychometric factor does indeed correspond to general intelligence as broadly defined. Such criteria are increasingly met in rodent studies but are strikingly underexplored in primates or birds.

Next, we will discuss different evolutionary theories that may explain why and how general intelligence can be widespread in nonhuman animals even though it is not immediately obvious how it can reliably produce fitness-enhancing behavior. We argue that the broad version of the cultural intelligence approach (Tomasello 1999; van Schaik \& Burkart 2011; van Schaik et al. 2012) can best account for the current body of evidence. We will end by proposing a model that construes the mind of both humans and nonhuman vertebrates as a mix of truly modular skills and seemingly modular skills that are ontogenetically constructed using general intelligence abilities. We will refer to them as primary and secondary modules, respectively. Species differences are likely with regard to the importance of these components, and we formulate tests to quantify their strength.

\subsection{The positive manifold and general intelligence}

Intelligence in humans has been intensely studied for more than a century (e.g. reviewed in Deary, Penke \& Johnson 2010; Nisbett et al. 2012). It is broadly defined as involving "the ability to reason, plan, solve problems, think abstractly, comprehend complex ideas, learn quickly and learn from experience" (Gottfredson 1997, p. 13). It is thus "not merely book learning, a narrow academic skill, or test-taking smarts. Rather it reflects a broader and deeper capability for comprehending our 
surroundings - "catching on," "making sense" of things, or "figuring out what to do." This definition has received broad acceptance (Nisbett et al. 2012). In animals, intelligence is thought to involve an individual's ability to acquire new knowledge from interactions with the physical or social environment, use this knowledge to organize effective behavior in both familiar and novel contexts, and engage with and solve novel problems (Byrne 1994; Rumbaugh \& Washburn 2003; Yoerg 2001). Thus, general intelligence, as defined in either humans or nonhuman animals, stresses reasoning ability and behavioral flexibility.

The concept of human general intelligence is built on one of the most replicated findings in differential psychology. In humans, performance across tasks of different cognitive domains is positively correlated: the positive manifold. Factor-analytical procedures applied to large data sets of individual performance across tasks consistently reveal a single factor that loads positively overall and can explain a significant amount of variation, often termed $g$ for (psychometric) general intelligence. Within this psychometric, factor-analytical approach, an individual's loading on this factor thus estimates its intelligence. Performance in specific cognitive tasks (e.g. Raven's Progressive Matrices) or test batteries (e.g. WAIS) is highly correlated with $g$, and is in fact often used as proxy measure for it, for instance in studies aimed at localizing $g$ in the brain (Burgess, Gray, Conway \& Braver 2011; Colom, Jung \& Haier 2006; Gläscher et al. 2010). In this paper, we will speak of general intelligence when referring to the broad definition of Gottfredson (1997) that stresses reasoning ability and behavioral flexibility, and of psychometric intelligence when referring to the entity estimated by the psychometric variable $g$. For humans, it is generally assumed that $g$ estimates general intelligence, based on the strong empirical correlations between the two, as reviewed below.

Psychometric intelligence, estimated through $g$, typically explains around $40 \%$ of variance in test performance, whereas the rest is explained by group factors and variance unique to specific tasks (Plomin 2001). It has been found that $g$ in humans has a clear genetic foundation (Davies et al. 2011), and in the absence of adverse environments that compromise the complete deployment of an individual's capacity, heritability can explain remarkably high proportions of variance (Joshi et al. 2015; Nisbett et al. 2012). Furthermore, $g$ has robust correlates in brain structure and function, such as brain size, gray matter substance, cortical thickness, or processing efficiency (Deary et al. 2010; Jung \& Haier 2007). However, rather than being localized in specific brain parts, it seems to be a system-level property of the brain (Pietschnig Penke, Wicherst, Zeiler \& Voracek 2015). Finally, $g$ is also a good predictor for various measures of life outcome, including school achievement, the probability of being in professional careers, occupational attainment, job performance, social mobility, and even health and survival. In particular, it is better at predicting such variables than specific cognitive abilities on their own (reviewed in Deary et al. 2010; Reeve 2004). 


\subsubsection{The structure of cognition}

The structure of human cognition continues to be debated (e.g. Ortiz 2015). Nonetheless, the presence of $g$ is now widely accepted due to the pervasive evidence from Carroll's (1993) seminal metaanalysis of over 460 carefully selected datasets on human cognitive ability. An influential account is Horn and Cattell's fluid-crystallized $g f-g c$ model (see also Major, Johnson \& Deary 2012). Fluid intelligence $g f$ refers to the capacity to think logically and solve problems in novel situations independently of previously acquired knowledge, and to identify patterns and relationships, whereas crystallized intelligence $g c$ refers to the ability to use skills, knowledge, and experience and crucially relies on accessing information from long-term memory. An explicit causal link from $g f$ to $g c$ is provided by Investment Theory (Cattell 1987), which is the developmental version of the $g f-g c$ model and finds considerable empirical support (Thorsen, Gustafsson, \& Cliffordson, 2014).

An integrated version, the so-called CHC (Cattell-Horn-Carroll) theory, has been supported by several studies and is a widely accepted consensus model (McGrew 2009). The CHC model is hierarchical, placing a general factor $g$ at the top, which affects both $g f$ and $g c$. Most current models involve some hierarchical structure involving a general factor, $g$, and fluid intelligence, $g f$ (but see for instance Major, Johnson \& Deary 2012; van der Maas, Dolan, Grasman, Wicherts, Huizenga \& Raijmakers 2006; Bartholomew, Deary \& Lawn 2009). In fact, some have argued that $g f$ and $g$ represent the same entity (Kan et al. 2011), and the previously mentioned definition of intelligence in a broad sense in fact emphasizes elements of both constructs.

Some models of general intelligence that do not involve $g$ are also still being considered. Van der Maas et al. (2006) for instance have presented a dynamic model of general intelligence that assumes independent cognitive processes early in ontogeny. Over the course of development, the positive manifold emerges because of mutually beneficial interactions between these initially independent processes. To the extent that one agrees to equate general intelligence with the positive manifold, the mutualism model may be viewed as a model of general intelligence for human and nonhuman animals in which variation between species would reflect the extent to which mutually beneficial interactions between cognitive processes arise during development. Since across species, bigger brains require more time to mature than smaller brains (Schuppli, Isler \& van Schaik 2012), and thus have more opportunities to develop such mutually beneficial interactions, such a scenario is compatible with an evolutionary perspective.

\subsubsection{Executive functions and intelligence}

Closely related to general intelligence are executive functions, or EFs (Barbey et al. 2012; Blair, 2006). EFs refer to "general-purpose control mechanisms that modulate the operation of various 
cognitive subprocesses and thereby regulate the dynamics of human cognition" (Miyake, Friedman, Emerson, Witzki, Howerter \& Wager 2000, p. 50). In other words, they are "a family of top-down mental processes needed when you have to concentrate and pay attention, when going on automatic or relying on instinct or intuition would be ill-advised, insufficient, or impossible" (Diamond 2013, p. 136). Three core EFs can be distinguished, namely inhibitory control (behavioral inhibition, cognitive inhibition and selective attention), working memory (Baddeley 2010), and cognitive flexibility.

Various measures of EFs have shown strong correlations with $g / g f$. Whereas the average correlation between working memory and $g$ is 0.72 , in some studies using latent variable analysis, it even reached identity (Colom, Abad, Rebollo \& Shih 2005; Nisbett et al. 2012), leading some authors to suggest that the two cannot be distinguished from each other (Royall \& Palmer 2014). That $g$ and EF are closely related is consistent with two further lines of evidence. First, working memory can be trained, and these training gains can translate into gains in general intelligence, even though not all procedures are effective and it is not always clear whether the training affects working memory per se or instead improves learning strategies (reviewed in Klingberg 2010; Morrison \& Chein 2011; Nisbett et al. 2012; Shipstead, Redick \& Engle 2012). Second, growing up bilingually, which makes high demands on a variety of EFs on a routine basis, is associated with stronger EFs in non-linguistic contexts, and thus with $g$ (Abutalebi \& Clahsen, 2015; Bialystok, Craik \& Luk, 2012; Rabipour \& Raz 2012). Nonetheless, because EFs do not provide the logical problem-solving functions and learning that are the hallmark of general intelligence (Embretson 1995), some aspects of general intelligence are independent of EFs.

In sum, evidence for domain-general intelligence in humans, estimated by the first factor derived in psychometric, factor-analytical approaches, is pervasive and backed up by neurobiological evidence and various correlates of life-outcome measures. The psychometrically derived $g$ factor is thus consistent with the broad notion of general intelligence, which stresses reasoning ability and behavioral flexibility and invokes cognitive processes such as learning and remembering, planning and executive functions. This conclusion raises the question of the evolutionary origin of general intelligence in humans, which we will address by reviewing recent developments in the nonhuman literature. To do so, we will review evidence for $g$ in animals, and whether it is warranted to assume that $g$ in animals is also consistent with a broader notion of general intelligence.

Intelligent behavior needs to be distinguished from behavior that may appear intelligent but lacks flexibility. Intelligent behavior in animals is often referred to as behavior that shows some degree of flexibility and emanates from some kind of mental representation rather than immediate perception only (Tomasello \& Call 1997). For instance, when digging wasps are interrupted anywhere in the sequence of actions involved in measuring the size of a hole to place a larva together with a prey item into it, they must start again at the very beginning of the behavioral sequence (Wooldridge 1968). Thus, many 
behaviors that at first sight look like they are the product of reasoning or learning turn out to be inflexible adaptations or modules (Sherry 2006). A collection of such dedicated adaptations presumably represents the ancestral state (e.g. Shettleworth 2012), and thus the null model against which the hypothesis of general intelligence has to be tested. Before turning to nonhuman animals, we will therefore provide an overview of domain-specific, modular conceptions of the mind that have been put forward particularly, but not exclusively, by evolutionary psychologists.

\subsection{Cognitive adaptations and domain specificity}

A domain-general factor of intelligence can be contrasted with domain-specific cognitive mechanisms or adaptive specializations (Cosmides \& Tooby 2002). The basic idea is that whenever a fitness-relevant cognitive problem arises repeatedly and predictably over long periods of time in a given species, natural selection favors a genetically based, developmentally canalized ('hardwired') solution to this problem. For instance, natural selection may provide a species with a particularly strong spatial memory to retrieve stored food, without endowing it with more powerful cognitive capacities in other contexts (Sherry 2006). Importantly, domain-specific mechanism cannot be used in domains other than the ones for which they evolved, whereas domain-general mechanism can be used to solve problems across domains.

Thus, the mind of animals, including humans, can be conceived of as a collection of adaptive specializations, often construed as modules, each of which evolved to solve a specific adaptive problem (Duchaine, Cosmides \& Tooby 2001). Notice that a mind uniquely made up of these kinds of specific adaptations is arguably incompatible with standard accounts of intelligence, because virtually no learning and flexibility are involved. Similarly, none of these specific cognitive adaptations require the presence of the domain-general processes underlying intelligence such as executive functions.

\subsubsection{Modularity and general intelligence}

A modular organization of mind is particularly appealing to evolutionary thinking because modular systems allow parts to be removed, added or modified without affecting the function of the structure as a whole. Therefore, modular systems may be more evolvable or even the only evolvable systems (Clune, Mouret \& Lipson 2013; Pavlicev \& Wagner 2012; Ploeger \& Galis 2011; Schlosser \& Wagner 2004; Shettleworth 2012). Thus, whenever conditions are sufficiently stable or at least predictable across generations, natural selection should favor solving recurrent fitness problems via modules rather than via general cognitive processes, because the former solve these problems on average quickly, effortlessly and efficiently (Cosmides et al. 2010) and can presumably evolve more readily. General intelligence, in contrast, is thus expected to evolve under conditions of social or environmental 
unpredictability. Solutions to these evolutionarily novel problems have to be acquired effortfully, via slow learning (e.g. Geary \& Huffmann 2002; Geary 2005).

The advantages of a modular solution to recurrent fitness problems, however, are not necessarily as straightforward. First, the fundamental assumption that a modular solution is indeed more evolvable can be questioned on both empirical and conceptual grounds (e.g., Anderson \& Finlay 2014; Lefebvre 2014; Bolhuis et al. 2011; d'Souza \& Karmiloff-Smith 2011). Empirical evidence for a direct mapping of specialized adaptive behavioral functions to specific modular neural units is actually rare, even for neural systems as simple as those from invertebrates. Novel adaptive functions seem mostly to be achieved via massive re-use of neural tissue rather than via the addition of encapsulated neuronal pools. Conceptually, the evolvability argument seems largely incompatibly with what is known about short-term neuromodulation, brain plasticity over the lifespan, response to damage, and ontogenetic principles of brain development. The a priori evolvability argument therefore does not lead to an unambiguous conclusion as to the superiority of domain-specific over domain-general organization.

Second, the other advantage of modularity, i.e. fast, effortless, and ultimately efficient solving of evolutionarily recurrent fitness problems, may only hold for particular notions of modularity, such as Fodorian modules (Fodor 1983). These are thought to be domain-specific functional units that process distinctive input stimuli using distinctive mechanisms. In particular, a module is thought to exclusively process information from a specific domain and to produce a correspondingly specific output in the form of representations and/or a behavioral response. Fodor listed criteria that must - at least to "some interesting extent" - be fulfilled by a functional unit to qualify as modular. These criteria include domain specificity, mandatory processing, high speed, production of shallow outputs (i.e. not requiring extensive processing), limited accessibility, a characteristic ontogeny (reliable emergence without explicit learning), a fixed neural architecture, and informational encapsulation (meaning it is not affected by other cognitive processes, a criterion thought to be particularly important). Paradigmatic examples of Fodorian modules are optical illusions. The presence of modules involving the processing of sensory information is widely accepted, and that their speed and efficiency are beneficial is obvious. However, a modular organization has also been proposed for more higher-level cognitive processes including ones related to folk psychology (e.g. processing of faces and facial expressions, Theory of Mind, cheater detection), folk biology (e.g. animate-inanimate distinction, flora-fauna) or folk physics (e.g. movement trajectories, gravity biases, representation of space, solidity and causality; summarized in Geary 2005). Indeed, massive modularity accounts hold that the mind is exclusively made up of modules (Barrett 2015; Carruthers 2005; Sperber 2001).

Massive modularity would appear to be irreconcilable with general intelligence (and therefore with the ability to solve evolutionarily novel problems), but much of the long-standing controversy about 
the massive modularity hypothesis of the human mind comes down to the use of different notions of modularity (see also Barrett \& Kurzban 2006). Indeed, a variety of highly divergent notions have developed (Barrett 2015; Barrett \& Kurzban 2012; Chiappe \& Gardner 2012; Coltheart 2011; Grossi 2014; Mahon \& Cantlon 2011), and many of these are much broader than the Fodorian one (e.g. Sternberg 2011). Because they also encompass the possibility of overarching, central control processes (Carruthers 2011), they are entirely compatible with the co-existence of domain-general processes and general intelligence (Barrett 2015; Carruthers 2011). In fact, Carruthers (2011) argues that most modules are specialized learning systems. Such broad notions of modularity, however, arguably no longer support the original idea of automatically providing fast and frugal solutions to recurrent fitness problems.

Unlike many proponents of massive modularity in humans, comparative behavioral biologists and comparative psychologists typically refer to notions of modularity that hew closely to the classical Fodorian modules, i.e. dedicated, inflexible cognitive adaptations that have evolved in response to specific recurrent fitness-relevant problems (e. g. Fernandes, Woodley \& te Nijenhuis 2014; Shettleworth 2012). Functional specialization here is mostly used in the biological, ultimate sense, i.e. referring to the specific adaptive pressures that gave rise to the evolution of specific dedicated modules. This perspective is grounded in research traditions such as neuroecology (Sherry 2006) that have provided empirical evidence for the occurrence among animals of dedicated cognitive adaptations, such as spatio-temporal memory abilities in food caching species, in particular birds (Brodin 2010, Pravosudov \& Roth 2013). These cognitive adaptations typically do not generalize to problems for which they did not evolve.

A mind composed of such dedicated adaptations represents a plausible null model, and indeed a plausible ancestral state of vertebrate cognition. Dedicated adaptations and general intelligence can obviously coexist (e.g. Geary 2005; Cosmides et al. 2010), for instance when the output of modules serve as inputs for intelligent reasoning, which may be responsible for the fact that in humans general intelligence predicts reasoning ability even in evolutionarily familiar contexts (Kaufman et al. 2011). The key questions with respect to the evolution of general intelligence therefore are how central, domaingeneral processes could evolve on top of domain-specific adaptations, whether and to what extent they also exist in nonhuman animals, and what adaptive benefits drove their evolution.

\subsubsection{Adaptive canalization beyond modularity}

Strictly domain-general approaches that construe the mind as a general-purpose computer face several well-known problems (Cosmides \& Tooby 1994; Cosmides et al. 2010; Frankenhuis \& Ploeger 2007; Heyes 2003; Kolodny, Edelman \& Lotem 2015, see also Table 1). First, an agent has to efficiently identify relevant information and filter out irrelevant information in the process of problem solving, a challenge known as the frame problem. Second, once the relevant information has been identified, the 
agent has to decide what to do with it. To do so, she has to solve the problem of how to pick and combine correct, adaptive behavioral options or cognitive processes out of an exponentially growing number of possibilities (the problem of the combinatorial explosion) or to learn important associations and skills in a limited period of time despite dealing with relevant stimuli that occur at a low rate (the poverty of the stimulus problem). Third, correct responses have to be made quickly and efficiently (the urgency problem). And fourth, while doing so, the agent has to find general, rather than only locally successful solutions (the functionality problem). It is thus beyond doubt that some canalization of cognitive processes is necessary.

Evolved Fodorian modules (referred to as cognitive adaptations by behavioral biologists and neuroecologists) are clearly one way of solving the problems highlighted above, in particular when they define the entire sequence from the acquisition of information to the adaptive behavioral response. However, they are not necessarily the only possible way, and natural selection may also overcome these problems in a different way that would allow domain-general abilities to evolve. A straightforward solution to this problem would be that domain-general abilities co-evolve together with adaptive canalizing mechanisms that guide how general abilities are applied. Canalizing mechanisms can have a phylogenetic origin, such as a genetically predetermined preference for a certain category of stimuli, e.g. the preference for faces in human infants (Shah et al. 2015). Alternatively, they can have an ontogenetic origin, such as the propensity of chimpanzees from tool-using communities to automatically perceive a stick as a potential tool, compared to genetically indistinguishable chimpanzees from non-tool-using communities who do not recognize this affordance (e.g. Gruber et al. 2011).

Table 1 summarizes the phylogenetic and ontogenetic canalizing mechanisms that ensure that domain-general cognition produces adaptive behavior despite the problems highlighted above. Unlike Fodorian modules, these mechanisms do not define the entire sequence from signal detection to behavioral output, but may be deployed at different stages during information processing. We will now examine the evidence for such domain-general canalization processes.

The first problem an individual faces is what to attend to in the continuous stream of stimuli coming in from different sensory modalities. This can be solved by innate dispositions or data-acquisition mechanisms (also referred to as phylogenetic inflection: Heyes 2003). Importantly here, innateness is not equivalent to inflexibility because innate dispositions to pay attention to one stimulus over another can be conditional. For instance, an animal foraging for berries may have an attentional bias to perceive small red entities, but the same animal when exposed to a raptor will be biased to only perceive potential hideouts. Alternatively, animals can learn ontogenetically which targets are particularly worth attending to (ontogenetic inflection). Here, social guidance of attention may play a particularly important role. Ontogenetic inflection automatically arises whenever immatures follow the mother and later other 
conspecifics, and is even more powerful in species that follow gaze (Shepherd 2010). In many species, including humans, immatures are particularly attracted to everything conspecifics are interacting with, and immatures of some species, such as aye-ayes (Krakauer, 2005), marmoset monkeys (Voelk1, Schrauf \& Huber 2006), or orangutans (Forss, Schuppli, Haiden, Zweifel \& van Schaik 2015) are highly neophobic toward stimuli they have not witnessed their mother or other familiar conspecifics interact with. Natural selection can therefore favor the disposition to preferentially use social information to decide which stimuli to attend to, and thus leave the specific target of attention largely unspecified. 
Table 1: Overview of some specific problems that a domain-general cognitive apparatus has to overcome in order to produce ultimately adaptive behavior, as well as potential solutions, i.e. adaptive canalization mechanisms. Note that these solutions may be very general themselves, such as a preference for social learning. See text for references.

\begin{tabular}{|c|c|c|}
\hline PROBLEM & $\begin{array}{l}\text { DOMAIN-GENERAL } \\
\text { CANALIZATION } \\
\text { PROCESSES }\end{array}$ & EXAMPLES \\
\hline $\begin{array}{l}\text { The frame problem: } \\
\text { What to attend to? }\end{array}$ & $\begin{array}{l}\text { Input filters (phylogenetic } \\
\text { inflection) } \\
\text { Socially guided attention } \\
\text { (ontogenetic inflection) }\end{array}$ & $\begin{array}{l}\text { Facilitated detection of small } \\
\text { red entities (when hungry) or } \\
\text { dark openings (when chased) } \\
\text { Immatures following mothers, } \\
\text { or following mothers' gaze }\end{array}$ \\
\hline $\begin{array}{l}\text { Problems of combinatorial } \\
\text { explosion and poverty of } \\
\text { stimulus } \\
\text { What to do with the } \\
\text { information? }\end{array}$ & $\begin{array}{l}\text { Direct triggering, prepared } \\
\text { learning } \\
\text { Socially guided learning } \\
\text { Integration with core }_{\text {knowledge }}^{1}\end{array}$ & $\begin{array}{l}\text { Flight reactions, learning to be } \\
\text { fearful of snakes but not } \\
\text { flowers } \\
\text { Copying how to extract food } \\
\text { from a matrix } \\
\text { Embedding the expectation } \\
\text { that objects always fall down } \\
\text { in a straight line (gravity bias) } \\
\text { with knowledge of solidity }\end{array}$ \\
\hline $\begin{array}{l}\text { The urgency problem: } \\
\text { How to reach a quick, efficient } \\
\text { response? }\end{array}$ & $\begin{array}{l}\text { Innate response tendencies } \\
\text { Acquired response tendencies } \\
\text { (automatization, secondary } \\
\text { modules) }\end{array}$ & $\begin{array}{l}\text { Evolved modules, evolved } \\
\text { heuristics (primary modules) } \\
\text { E.g. learned heuristics to solve } \\
\text { algebraic equations (secondary } \\
\text { modules) }\end{array}$ \\
\hline $\begin{array}{l}\text { The functionality problem: } \\
\text { How to find generally, not only } \\
\text { locally successful solutions? }\end{array}$ & $\begin{array}{l}\text { Innate goals } \\
\text { Socially acquired end-state } \\
\text { preferences }\end{array}$ & $\begin{array}{l}\text { Innate template of a safe } \\
\text { burrow, or of good food } \\
\text { Learn by following mother } \\
\text { what a good sleeping place is; } \\
\text { copy the goals of successful } \\
\text { individuals, conformity biases }\end{array}$ \\
\hline
\end{tabular}

${ }^{1}$ i.e. evolved cognitive domains that are fleshed out with experience; e.g. Gelman (1990).

In a second step, the individual has to "decide" what to do with the stimuli that have captured its attention, since input mechanisms filter incoming stimuli but do not produce behavior. Subsequent processes are therefore required to determine what to do with these stimuli without being stymied by the problems of poverty of stimulus and the combinatorial explosion. First, in the case of phylogenetic inflection, co-evolution of input mechanisms and response tendencies is frequent (Lotem \& Halpern 2012), as when a moving stimulus in the sky automatically triggers a flight reaction, but also when individuals are more likely to associate a snake (but not a flower) with fear (Cook \& Mineka 1989), or a taste (but not an auditory stimulus) with subsequent nausea (known as biologically prepared learning or the Garcia effect: Garcia \& Koelling 1966). Second, in the case of ontogenetic inflection, social learning can also affect how the individual processes a stimulus that has come to its attention. Third, the stimuli 
that have attracted an individual's attention may be integrated with innate bodies of knowledge, so-called core knowledge (Gelman 1990; Spelke \& Kinzler 2007) or psychological primitives (Samuels 2004), and so give rise to more elaborate skills and conceptual systems (Carey 2009).

A third problem for the individual is that decisions often have to be made under time pressure (the urgency problem). Evolved modules, heuristics, or direct and reflexive triggering of responses are particularly good at providing fast responses because they bypass central processes. But quick and efficient responses can also be achieved in evolutionarily novel contexts, such as solving algebraic equations or playing chess, if a learned heuristic approach becomes an automated subroutine and can be applied effortlessly (Bilalić, Langner, Ulrich, \& Grodd 2011; Chang 2014). Such problem solving has similar surface properties to modular organization sensu Fodor. This fact has sometimes led to conceptual misunderstandings (see also 1.2.3), and is relevant for approaches that try to identify domain-general processes in nonhuman animals (see also 2.4.3).

A final potential problem is that developmentally acquired response tendencies may be successful in solving local problems, but nevertheless may not ultimately help an individual survive and reproduce (the functionality problem). Individuals, be they animals or humans, typically do not represent ultimate fitness goals in their everyday behavior. Rather, they pursue a set of innate psychological goals, which on average results in fitness-enhancing behaviors (Tinbergen 1963) but also explains why they may become maladaptive in environments other than the one in which the goals evolved, as shown by our strong preferences for sweet, fatty and salty foods. However, innate goals may be modified or supplemented by socially acquired end-state preferences. For immatures, who are most strongly affected by the canalization problems listed in Table 1, copying successful adult individuals is widespread and generally results in adaptive behavior because they are copying individuals who have survived until adulthood and managed to reproduce. Socially acquired end-state preferences and goals are particularly widespread in humans, who are highly susceptible to conformity and prestige biases (Dean, Vale, Laland, Flynn \& Kendal 2014; Richerson et al., 2016). Increasing evidence also suggests the existence of such biases in at least some nonhuman primates and birds (Aplin et al. 2015; Kendal et al. 2015; Luncz \& Boesch 2014; van de Waal, Borgeaud \& Whiten 2013).

Despite being incomplete, Table 1 serves to highlight that adaptive canalization of cognition not involving Fodorian modules is possible, indeed potentially quite frequent. It also highlights the prominent reliance on social inputs to overcome the canalization problems inherent to domain-general mechanisms. Social learning is broadly defined in the animal literature, i.e. learning that is influenced by observation of, or interaction with, another animal or its products (Heyes 1994, see also Box 1984). It is widespread in the animal kingdom, both in vertebrates and invertebrates, and ranges from processes as simple as social facilitation and enhancement learning to observational forms of social learning such as true imitation (e.g. 
Hoppitt \& Laland 2013). Interestingly, it is increasingly assumed that many of the cognitive mechanisms involved in social learning are of general nature rather than specialized and specific to social learning (Behrens, Hunt, Woolrich \& Rushworth, 2008; Heyes, 2012, 2016). Indeed, all forms of social learning also include a major element of individual learning. This is most evident in forms such as stimulus enhancement, where the attention of a naïve individual is drawn to stimuli other individuals are interacting with, which then releases individual exploration, play, and trial-and-error learning with this stimulus. Individual learning and practice, however, are also involved in the acquisition of skills through imitation learning, where it is typical that after observation, a phase of individual practice is required (Jaeggi et al. 2010; Schuppli et al. in press; Galef 2015). Thus, natural selection for social learning seems to automatically trigger selection on individual learning and general cognitive ability, suggesting that ontogenetic canalization through social learning may have contributed to enabling the evolution of domain-general cognition, an issue to which we will return in section 3.3.

\subsubsection{Primary and secondary modularization, and implications for general intelligence in nonhuman animals}

Evolved Fodorian modules have specific surface properties: they work fast, effortlessly, and automatically, and they do not require significant amounts of executive control and working memory. Nevertheless, identifying modules in animals based on these properties is problematic because skills, capabilities and solutions to problems that are acquired through effortful problem-solving and learning based on general cognitive processes may become automatized over time, a process we refer to as secondary modularization. After such secondary modularization, or automatization, these skills have many of the surface properties in common with primary, evolved Fodorian modules. Note that this distinction in primary and secondary modularization is analogous to the distinction in primary and secondary cognitive abilities by Geary (1995), but whereas the latter has been developed specifically for humans, the former is thought to apply to a broad array of animal species.

Despite the similarities in surface properties, primary and secondary modules differ fundamentally with regard to their origin (Table 2): primary modules are evolved adaptations with canalized, buffered development, whereas secondary modules represents ontogenetically acquired skills that were automatized during ontogeny. In fact, secondary modularization is particularly common during the immature period (d'Souza \& Karmiloff-Smith 2011). A consequence of the different etiology of primary and secondary modules is that the latter are more variable in their content and distribution across individuals or populations of the same species. Since little is known about the ontogeny of many of the specialized cognitive modules postulated for humans (Geary 2005), we should also acknowledge the possibility that some or all of these are secondary rather than primary (Anderson \& Finlay 2014) or at 
least subject to experiential influences. For instance, even some prototypical modules such as those involved in face perception depend on experience (Dahl, Chen \& Rasch 2014).

Table 2: Primary and secondary modules differ with regard to their etiology and development, which has implications for their content and distribution within a species or population.

\begin{tabular}{|l|l|l|l|l|l|}
\hline & Etiology & Development & $\begin{array}{l}\text { Content of } \\
\text { skills }\end{array}$ & Distribution & Examples \\
\hline $\begin{array}{l}\text { Primary } \\
\text { modules }\end{array}$ & $\begin{array}{l}\text { Evolutionary; } \\
\text { reflect natural } \\
\text { selection for } \\
\text { domain-specific } \\
\text { cognitive } \\
\text { adaptation }\end{array}$ & $\begin{array}{l}\text { Skill matures, } \\
\text { motor } \\
\text { practice } \\
\text { (experience- } \\
\text { expectant }{ }^{1} \text { ) }\end{array}$ & $\begin{array}{l}\text { Pre-set, highly } \\
\text { predictable }\end{array}$ & $\begin{array}{l}\text { Uniformly } \\
\text { present in a } \\
\text { given species }\end{array}$ & $\begin{array}{l}\text { Tendency of (young) } \\
\text { felids to respond to small } \\
\text { moving objects with } \\
\text { behaviors from the } \\
\text { hunting repertoire }\end{array}$ \\
\hline $\begin{array}{l}\text { Secondary } \\
\text { modules }\end{array}$ & $\begin{array}{l}\text { Ontogenetic; } \\
\text { reflect behavioral } \\
\text { flexibility and } \\
\text { learning ability, } \\
\text { acquisition often } \\
\text { based on EFs }\end{array}$ & $\begin{array}{l}\text { Skill is } \\
\text { learned } \\
\text { (experience- } \\
\left.\text { dependent }{ }^{1}\right) \\
\text { and practiced } \\
\text { to the point } \\
\text { of } \\
\text { automaticity }\end{array}$ & $\begin{array}{l}\text { More variable, } \\
\text { netermined by } \\
\text { nature of inputs }\end{array}$ & $\begin{array}{l}\text { Variable } \\
\text { among } \\
\text { individuals, } \\
\text { populations }\end{array}$ & $\begin{array}{l}\text { Automatic perception of a } \\
\text { stick as potential tool in } \\
\text { some apes; learned } \\
\text { algorithms to solve } \\
\text { algebraic equations in } \\
\text { humans }\end{array}$ \\
\hline
\end{tabular}

Note. ${ }^{1}$ Greenough et al. 1987.

The implication for the question of general intelligence in nonhuman animals is that it is no longer possible to uniquely rely on surface properties such as speed, effort, efficiency and reliability to infer the presence of evolved domain-specific modules, because secondary modules have similar properties. Instead, a better diagnostic tool for the presence of general cognitive abilities is the presence of variable skill profiles across individuals and genetically similar populations due to secondary modularization (see 2.4.3).

We have shown that human cognition involves elements of domain-specific and domain-general processes, but that the same can potentially be true for animals as well. Hence, animal minds need not be bundles of specialized cognitive adaptations. Having thus leveled the playing field, we will first, in section 2, review recent evidence for whether the positive manifold $(g)$ is present in nonhuman animals at all, and if so, how such a $g$ factor is best explained. In particular, we will focus on the question whether such psychometric intelligence shows any of the features usually referred to as general intelligence. Even if we can be confident that this is the case in humans, whether the same applies to animals must be an empirical question (Galsworthy, Arden \& Chabris 2014) and we highlight different research strategies that may prove to be fruitful in the future. In section 3, we will then use this pattern of results to examine the ultimate evolutionary question of why general intelligence evolved, and which selection pressures may have favored it. 


\section{General intelligence in nonhuman animals?}

Unless general intelligence is inextricably linked to language, considerations of evolutionary continuity suggest that nonhuman animals, especially our closest extant relatives, the great apes, may well possess it too, at least to some extent. The presence of evidence for executive functions in animals (Chudasama 2011) supports this contention, as does the overall flexibility of brains in animals, both during development and as response to experience, including the training of cognitive skills (JohansenBerg 2007; Sale et al. 2014; Matsunaga et al. 2015; Kolb \& Gibb 2015). According to most neurobiologists, such developmental plasticity is incompatible with purely domain-specific descriptions of cognitive abilities (Quartz 2003; Prinz 2006; Anderson \& Finlay 2014). Nonetheless, evolutionary plausibility does not amount to empirical evidence, to which we turn now.

The question of whether general intelligence is unique to humans has typically been addressed by asking whether we find a positive manifold or psychometric intelligence, by following two complementary approaches: First, within a given species, in analogy to human studies, psychometric test batteries have been applied to many individuals. Second, broad comparative analyses (both experimental and meta-analytical) have been conducted across species to investigate whether species differ from each other in general intelligence, rather than in specific cognitive adaptations. In addition, some studies have simultaneously analyzed intra-specific and inter-specific variation in cognitive performance. In the following subsections, we will first give an overview of these studies. We will refer to general factors extracted from intra-specific studies as $g$, and to those extracted from inter-specific studies as $G$. We will then critically assess to what extent alternative explanations may account for the findings, and formulate criteria for future studies that should help pinning down to what extent a statistically derived $g / G$ factor reflects general intelligence as broadly defined.

\subsection{Intra-specific studies of psychometric intelligence: $g$}

Interest in the question of whether general intelligence may be found in nonhuman animals briefly spiked in the 1930s and 40s (Locurto \& Scanlon 1998), after Spearman's $g$ factor (Spearman 1927) had become widely known. These studies reported positive correlations across various types of tasks, but predominantly concerning mazes and mostly in non-primate species such as mice, rats and chicks (Locurto 1997). Because the model of a hierarchical structure of human cognition and the methodological tools to detect it became widely available only in the late 1940s, the design of these early studies was often not suitable to detect $g$ or any factor structure.

For the next half a century, the question of animal general intelligence was largely ignored, with interest resurging only after the late 1990s, mainly focusing on mice and primates. Table 3 (note that Tables 3-5 are inserted after the main text) provides an overview of these studies that have assessed and 
analyzed correlated performance across three or more cognitive tasks within subjects of the same species, for rodents, primates, and other species (see also Chabris 2007; Matzel et al. 2013; Bouchard 2014; Galsworthy et al. 2014).

In rodents, robust evidence for $g$ is available from a range of studies, mostly on mice, from test batteries including as many as eight different tasks and various regimes of principal component analysis (e.g. reviewed in Matzel, Wass \& Kolata 2011; Galsworthy et al. 2014; Bouchard 2014; but see Locurto et al. 2003, 2006). In general, $g$ explains between $30 \%$ and $40 \%$ of variation in cognitive performance, and in rats, it is positively correlated with brain size (Anderson 1993). Moreover, heritability estimates of up to $40 \%$ have been reported (Galsworthy et al. 2005). Test batteries often include typical, rather basic learning tasks, such as associative fear conditioning, operant avoidance, path integration, odor discrimination and spatial navigation. Nevertheless, as in humans, the derived $g$ factors have been shown to covary with executive functions, such as selective attention (Kolata et al. 2007; Matzel, Light, Wass, Colas-Zelin, Denman-Brice, Waddel \& Kolata 2011) and working memory (in particular working memory capacity: Kolata et al. 2005; Matzel et al. 2008; Sauce et al. 2014) as well as performance in tests of reasoning. For instance, $g$ derived from a standard mouse test battery predicted performance in inductive (finding efficient search strategies in a complex maze) and deductive reasoning (inferring the meaning of a novel item by exclusion, i.e. "fast mapping": Wass et al. 2012). Working memory training did increase $g$ (Light et al. 2010, Matzel et al. 2011), mainly through its positive effect on selective attention (Light et al. 2010; see also Sauce et al. 2014). Importantly, $g$ does not simply capture fear and stress reactivity (Matzel et al. 2006), anxiety (Galsworthy et al. 2002) or other lower-level biological processes such as sensory or motor abilities (Matzel et al. 2006). In sum, for rodents, the finding of a first component in cognitive test batteries that corresponds to $g$ is robust and several implications of its presence have been confirmed.

In nonhuman primates, only a handful of studies on the consistence of individual-level differences in cognitive tasks are available. Herndon, Moss, Rosene, and Kiliany (1997) were interested in classifying patterns of age-related cognitive decline in adult rhesus macaques, an Old World monkey species. They found a first PCA factor that explained $48 \%$ of the variance in cognitive performance and on which all six tasks loaded positively. This factor, based on 30 subjects, was highly correlated with a factor derived from a subset of only three of these tasks (all of which, again, loaded positively on it) in an overlapping sample of 53 subjects. Furthermore, this putative $g$ declined linearly with increasing age of the monkeys.

Banerjee et al. (2009) found evidence for $g$ in a New World monkey species, the cotton-top tamarin (Saguinus oedipus). They tested 22 subjects with a battery consisting of 11 tasks that assess a range of cognitive abilities such as inhibitory control, quantity discrimination and memory. Owing to the 
relatively high number of missing individual test scores, they used Bayesian analysis and found a $g$-factor but no group factors that would have corresponded to more specialized cognitive domains (although the a priori classification of domains is inevitably tenuous without extensive validation; see also section 2.4).

Among great apes, evidence for $g$ is more mixed. Herrmann et al. (2007) developed the Primate Cognitive Test Battery (PCTB) consisting of 16 tasks from the physical and the social domain, a priori placed into six categories (i.e. space, quantities, causality and social learning, communication, and Theory of Mind) and applied it to 106 chimpanzees, 32 orangutans, and 105 two-year old human children. Chimpanzees and human children performed equally well (and better than orangutans) in tasks from the physical domain but the children outperformed both ape species in the social domain. These results were not consistent with $g$ in any of the species, including human children. To explicitly address the structure of individual differences, Herrmann et al. (2010a) re-analyzed the data from the chimpanzees and children in 15 of the 16 PTCB tasks (tool-use was not included) using a confirmatory PCA (see 2.4.1 for further discussion). They found a different structure of cognitive abilities for chimpanzees ( 2 factors) and children ( 3 factors). In addition to a "Spatial" factor in both species, only one additional "Physical-Social" factor emerged in chimpanzees, whereas two additional factors, a "Physical" and a "Social" one, emerged in children. The authors thus did not find evidence for $g$ in either chimpanzees or humans. However, human test batteries typically do not include subtests assessing social cognition. In fact, the relationship between general cognitive processes and socio-cognitive processes is currently poorly understood in humans (Korman et al. 2015). However, this problem does not explain the presence of two other factors rather than a single $g$ in human children.

More recently, Hopkins et al. (2014) tested 99 chimpanzees with a reduced and slightly modified version of the PCTB consisting of 13 of the 16 tasks (including tool use but excluding one of two quantity tasks, the social learning task, and one theory of mind task). They report a $g$ factor derived from a nonrotated PCA and used quantitative genetic analyses to estimate its heritability $\left(\mathrm{h}^{2}\right)$, which was found to be $53 \%$ and highly significant. Furthermore, the results remained stable when 86 of the 99 chimpanzees were retested with the same test battery after two years, and were confirmed with parallel analysis. Woodley of Menie et al. (2015) further analyzed the data set and concluded that the more $g$-loaded a task is, the higher its heritability and phenotypical variability, as also found in humans. The more $g$-loaded tasks also had higher coefficients of additive genetic variance, suggesting that cognitive abilities with higher $g$-loadings have been subject to stronger recent selection.

Taken together, then, the psychometric studies in specific rodent and primate species lend increasing support to the notion that the positive manifold is not unique to humans but also present in non-human animals. Studies on other lineages such as dogs (Nippak \& Milgram 2005, Arden \& Adams 2016) and birds (Keagy et al. 2011; Shaw et al. 2015) are also beginning to provide evidence. However, a 
serious limitation of psychometric studies in nonhuman animals is that they tend to lack power with respect to sample size, the diversity of cognitive tasks, or both. We will discuss these limitations below in section 2.4. Fortunately, there is a complementary approach, which examines interspecific variation and is particularly powerful to reveal evolutionary trends.

\subsection{Inter-specific studies of psychometric intelligence: $G$}

In comparative approaches, the fundamental question is whether some species systematically outperform others across an array of distinct cognitive tasks, consistent with the notion of psychometric and perhaps general intelligence, or whether species differences are instead characterized by independent variation in performance across tasks and domains, consistent with higher domain-specificity. Comparative studies thus investigate whether what evolves are specialized skills or rather general intelligence. This approach (Table 4) has predominantly been applied to primates but also to birds and involves both meta-analyses and targeted experimental comparisons.

For primates, Deaner et al. (2006) conducted a meta-analytical study that compared the performance of 24 primate taxa tested with 9 experimental physical-cognition paradigms using Bayesian hierarchical modeling (Johnson et al. 2002). They found strong evidence for $G$, which correctly predicted $85 \%$ of the species rankings (but note that caution is needed when comparing the proportion of explained variance between standard PCA and Bayesian analyses). Moreover, in a follow-up study, $G$ was strongly correlated with brain size (Deaner et al. 2007).

In another set of studies, Reader and Laland (2002) collected data from the literature on the incidence of innovation, social learning and tool use in 116 species of nonhuman primates, both in captivity and in the wild, and found that across species, all three measures were correlated with each other $\left(\mathrm{r}^{2}\right.$ values around 0.4$)$, as well as with brain size. In a follow-up study involving 62 primate species (Reader et al. 2011), they found evidence for general intelligence on the inter-specific level $(G)$ in principal component and factor analyses explaining $65 \%$ of the variance, based on measures of innovation, social learning, tool use, as well as extractive foraging and tactical deception. As in their earlier study, $G$ was correlated with brain size, but also with a combined measure of performance across several learning tasks, with learning set performance (both taken from Riddell \& Corl 1977), and the $G$ measure of Deaner et al. (2006).

More recently, Fernandes et al. (2014) compiled published data from five cognitive domains (innovation, tool use, social learning, extractive foraging, and tactical deception) across 62 primate species (data sets from Reader et al. 2002; and Byrne \& Whiten 1990). They found that a single factor $G$ explained almost $62 \%$ of the total variance. Furthermore, they report that cognitive abilities that load more strongly on $G$ show bigger inter-specific variation, weaker phylogenetic signals, and faster rates of 
evolution. These results are consistent with the idea that $G$ has been subjected to stronger selection pressure than narrow, more domain-specific abilities and that $G$ is thus the principal locus of selection in the evolution of primate intelligence (but see also 2.5).

The only other taxon to which comparative approaches have been applied are birds. As in primates, significant positive correlations across species were found between innovation rates in the wild, tool use, learning performance, and social learning. These studies also found positive correlations between innovation rates and brain size as well as colonization success (Ducatez, Clavel \& Lefebvre 2015; Lefebvre 2013; Lefebvre, Reader \& Sol 2004; Sol, Duncan, Blackburn, Cassey \& Lefebvre 2005).

\subsection{Mixed studies combining intra- and inter-specific variation}

Some studies have pursued a mixed approach by applying test batteries to multiple individuals from several species (Table 5). For instance, Herrmann \& Call (2012) analyzed data of 23 individuals from all four nonhuman great ape species, which were studied in a range of tasks from the physical domain, and found no support for the existence of $g$. Nevertheless, some subjects performed particularly well (or poorly) across tasks, both in the sample of 23 great apes and in the 106 chimpanzees mentioned above (Herrmann et al. 2010a), indicating that there was some consistency in individual performance.

In another mixed study, Amici et al. (2012) found no evidence for $G$ or $g$ when re-analyzing data from seven primate species (all four great ape species, long-tailed macaques, spider monkeys, and capuchin monkeys, totaling 99 individuals) from 17 cognitive tasks. In the Bayesian approach used to analyze the data (see also Barney, Amici, Aureli, Call \& Johnson 2015), the 17 tasks were a priori attributed to the domains of inhibition, memory, transposition and support, similar to Herrmann et al. (2010a).

In contrast to intra- and inter-specific studies, mixed studies thus provide less support for psychometric intelligence. Here, we offer a tentative suggestion to explain this absence of evidence for psychometric intelligence in mixed studies which will need to be examined in more detail in future work. First, despite including a large number of individuals overall, the effective sample size to identify $g$ remains the number of individuals within each species, and to identify $G$ is the number of species. This may strongly influence the outcome since in mixed studies the detection of $G$ is not based on average species-specific performance as is done in inter-specific studies, but based on individual values, which are more susceptible to noise. A recent memory task illustrates the superiority of species averages in estimating abilities at the species-level. In this study, both marmoset and squirrel monkeys as a group provided results fitting the Ebbinghaus forgetting curve, but at the individual level, several individuals did not, indicating that the performance of these individuals was strongly affected by noise (Schubiger et al. in press). Such noise may overshadow $G$, especially in species that are very close in $G$. 
A second issue is that in a sample of species with similar $G$ (e.g. taken from Deaner et al. 2006), and thus both the great ape study by Herrmann et al. (2012) and the study by Amici et al. (2012), speciesspecific predispositions linked to domain-specific adaptations may mask a $G$ effect. Thus, chimpanzees and orangutans are more extraction-oriented than bonobos or gorillas (van Schaik 2016), as expressed, for instance, in species differences in tendencies to handle objects (Koops et al. 2015), or to solve social problems (Herrmann et al. 2010b). Such variation is bound to produce species differences in mean performance on some but not on other tasks, reducing the correlation across tasks in the overall data set. Intraspecific comparisons obviously are not affected by this problem, whereas the effect on inter-specific comparisons is reduced the broader the comparison in terms of $G$ are, since major inter-specific differences in $G$ lessen the effects of species differences in domain-specific predispositions.

More generally, we can ask whether, if in a given lineage, a robust $G$ is found, this implies that all species in the comparison must have $g$, and vice versa. Several combinations of evidence for $g$ and $G$ are possible, in particular in mixed studies, as summarized in Table 6 , and we discuss likely explanations for these combinations.

Table 6: Summary of the potential combinations of evidence for $g$ and $G$, and under what conditions apparently conflicting findings can be reconciled.

\begin{tabular}{|c|c|c|}
\hline No evidence for $\boldsymbol{G}$ & $\begin{array}{c}\text { No evidence for } \boldsymbol{g} \\
\text { I: domain-specific cognitive } \\
\text { abilities }\end{array}$ & $\begin{array}{c}\text { II: } g \text { is present in only a few of the } \\
\text { species involved in the comparative } \\
\text { approach; or the involved species } \\
\text { are very close in } G \text { and evidence for } \\
\text { it is masked by variation in species- } \\
\text { specific predispositions }\end{array}$ \\
\hline Evidence for $\boldsymbol{G}$ & $\begin{array}{c}\text { III: largely cumulative modularity; } \\
\text { or artifact due to lack of power of } \\
\text { animal psychometric studies }\end{array}$ & $\begin{array}{c}\text { IV: general intelligence, in } \\
\text { particular if supported by external } \\
\text { validation of both } g \text { and } G\end{array}$ \\
\hline
\end{tabular}

The interpretation is straightforward whenever evidence for $g$ and $G$ point in the same direction (entries I and IV), and in case of constellation IV, can be externally validated separately at both the level of $g$ and $G$ (see also 2.5). One potentially conflicting constellation is when positive evidence for $g$ but no evidence for $G$ is available (entry II). Such a result can arise if $g$ is present in only a few of the species involved in the comparison, which might occur when distantly related lineages are compared. The other conflicting constellation (entry III) is that comparative studies provide evidence for $G$, but there is no evidence for $g$ within the species involved in the comparison. This was the case in some primate studies. 
In principle, it is possible that we are dealing with cumulative modularity and that by chance the distribution of modules across the species included in the sample is hierarchically nested. In this scenario, no correlation between $G$ and EFs or, arguably, brain size is expected, which is inconsistent with current findings. The most likely cause of constellation III, therefore, is lack of power of animal studies to reliably detect the absence of $g$, due to the small sample sizes and difficulties to construct a suitable test battery, which make animal psychometric $g$ studies prone to Type II errors (see also section 2.4.1).

Taken together, there is increasing evidence for $g$ in nonhuman animals, in particular mice and primates, for which positive evidence is available for New World monkeys, Old World monkeys and chimpanzees (but see Herrmann et al. 2010a). At the inter-specific level based on comparative analyses across species, studies of primates and birds provide a robust pattern consistent with $G$. Finally, mixed studies in primates that simultaneously analyze within- and between-species variation yield a more ambiguous pattern.

\subsection{Facts or artifacts?}

A legitimate concern is whether a presumptive $g / G$-factor can arise as an artifact, and a legitimate question is what exactly it corresponds to. We will now review why statistical or methodological artifacts may produce false positives, whereas secondary modularization may lead to false negatives, and formulate criteria for future directions that may be used to evaluate whether $\mathrm{g} / \mathrm{G}$ corresponds to general intelligence broadly defined.

\subsubsection{Statistical issues}

The use of PCAs or related procedures involves a suite of decisions, including whether exploratory or confirmatory analyses are applied, whether non-rotated or rotated factors are considered, and whether oblique or orthogonal rotations are used. A detailed discussion of factor analytical procedures is far beyond the scope of this review, and we refer readers to the specialized literature (e.g Barney et al. 2015; Garson 2013; Stevens 2012). However, because these decisions may critically affect the conclusions of animal studies, we must highlight some issues that appear relevant to the empirical results summarized above.

First, the use of confirmatory analyses requires an a priori decision of what a domain is, and which tasks are associated with the respective domains (this also applies to Bayesian approaches that likewise categorize tasks a priori to hypothesized domains: Amici et al. 2012; Barney et al. 2015). The identification of domains of animal cognition, however, is not straightforward. For instance, some classify spatial reversal learning tasks as spatial cognition (e.g. Locurto and Scanlon 1998) whereas others stress their inhibition component (Tapp et al. 2003). In reality, of course, subjects may recruit several specific 
abilities to solve a particular task, and in fact different subjects may even recruit a different mix. Accordingly, Hopkins et al. (2014) found that their exploratory PCA findings were not entirely consistent with the a priori structure of the PCTB originally proposed by Herrmann et al. (2007, 2010a). An a priori allocation of tasks to domains is thus not straightforward; in fact, the structure of a species' cognition is an empirical question (see also section 1.1.1 for corresponding efforts in human intelligence research). Accordingly, the use of confirmatory techniques may lead to diverging results compared to analytical approaches that are a priori agnostic with regard to factor structure.

Second, studies vary with regard to whether they present rotated or non-rotated solutions. Since rotations are designed to make the pattern of factor loadings more pronounced, it is generally recommended to use non-rotated solutions in $g$ studies (Galsworthy et al. 2014; Jensen \& Weng 1994; Locurto, Fortin \& Sullivan 2003; Plomin 2001; Woodley of Menie, Fernandes \& Hopkins 2015). Rotated and non-rotated solutions from the same data set are presented in Hopkins et al. (2014) and Woodley of Menie et al. (2015). Whereas the varimax-rotated solution (Hopkins et al. 2014, Table 1) appeared to suggest that a general factor $g$ was lacking, the results of non-rotated solutions, verified by parallel analysis, demonstrated it was in fact present.

Third, a common intuition in general intelligence studies on animals is to compare the amount of variance explained by a first factor, and to conclude that the higher the amount of explained variance, the stronger the evidence for $g$. In human studies, the first non-rotated factor typically accounts for about $40 \%$ of variance (Plomin 2001), which is in fact similar to what has been reported for mice (see Table 3). However, an exclusive focus on the amount of explained variance is problematic for empirical and conceptual reasons. Empirically, the proportion of explained variance not only depends on the statistical issues discussed above, but also on the heterogeneity of the subjects in the sample: the more heterogeneous, the higher the proportion of variance explained. In interspecific investigations, for instance, this means that studies that involve species that vary widely in general intelligence and brain size (e.g. 20 species of primates ranging from great apes to prosimians) will find higher proportions of explained variance than studies with a similar sample size, but where the species are all relatively similar (e.g. 20 different species from the same genus or taxonomic family). Conceptually, to the extent that the mind is a combination of both specialized cognitive adaptations and domain-general processes (see also section 4.1), very small proportions of explained variance may still be indicative of a real $g$. Likewise, a first factor with high loadings of some tasks but not others, may reflect the absence of general intelligence, but may also reflect the co-occurrence of a general factor and one or several additional, more specialized domains (e.g. for spatial orientation, see Herrmann et al. 2007; see also first PCA factor in Hopkins, Russell \& Schaefer 2014). 
Last but not least, the most severe statistical restriction of nonhuman psychometric studies is that they critically lack power due to their small sample sizes. Reaching a near-consensus about the structure of human intelligence required meta-analyses involving thousands of subjects (Carroll 1993). Obtaining sample sizes comparable to human studies is unrealistic for most nonhuman animal species, in particular for nonhuman primates (albeit less so for rodents). However, replicating studies is feasible, and if this reveals the same factorial solution in a different set of subjects, and if combining such data sets also increases the fit of the solution, we can be increasingly confident that we are not dealing with statistical artifacts. Unfortunately, while this approach minimizes Type I errors, it suffers from very limited power to avoid Type II errors. In other words, if successful, we can be confident that we have obtained a real result, but if it fails, this may either reflect the absence of a general factor or too low a number of subjects. This shortcoming highlights the need to use external validation for psychometric $g / G$ studies, as discussed below in section 2.5 .

\subsubsection{Methodological issues}

We now turn to the possibility that a $g / G$ factor may arise as a methodological artifact, because the results reflect variation in other underlying variables than general intelligence (see also Macphail's [1982] contextual variables) or because the tasks mainly tap into problems of the same domain.

Some individuals, or some species, may systematically outperform others not because they are more intelligent, but because they are less fearful and better habituated to testing, are more motivated to participate in tasks, have sharper senses or are simply more active than others (Macphail 1982). Ideally, such confounds are directly quantified, as for instance in Matzel et al. (2006). In a sample of 43 mice individuals, they examined to what extent the general learning ability $g$ extracted via PCA from a test battery of six cognitive tasks was correlated with 21 measures of exploratory behavior, sensory/motor function (e.g. running and swimming speed, balance tasks), activity, or fear/stress sensitivity. They found that $g$ was not explained by general activity, sensory/motor function, physical characteristics or direct measures of fear, but was correlated with several exploratory behaviors. Follow-up studies suggested that this link is caused by variation in habituation rates when exposed to potentially stressful situations (Light, Grossman, Kolata, Wass \& Matzel 2011) rather than by fearfulness influencing both exploration and task performance: treatment with anxiolytic drugs did increase exploratory behaviors but did not improve performance in individual tasks or $g$ (Grossman, Hale, Kolata \& Matzel 2007). Likewise, temporary environmental enrichment resulting in increased exploration tendency did not improve performance on the cognitive test battery (Light et al. 2008). Thus, exploration and $g$ may co-vary because more exploratory individuals are more likely to encounter contingencies in the environment that promote learning and problem solving, which over time leads to greater experience. The correlation between 
exploration and $g$ may thus reflect a long-term, cumulative effect of experience on $g$. This is in line with investment theory (Cattell 1987), and with findings in human infants, where the preference for novelty and habituation is positively correlated with later performance in IQ tests (Teubert, Vierhaus \& Lohaus 2011), but also with apes, where individuals more likely to approach novel objects and a human stranger performed better in physical cognition tasks (Herrmann et al. 2007). Thus, the rodent studies support the idea that $g$ is not an artifact of confounding factors.

Another non-cognitive factor that may explain variation in cognitive performance is motivation to participate. Female callitrichid monkeys have been reported to outperform males in problem-solving tasks (Brown, Kaplan, Rogers \& Vallortigara 2010; Yamamoto, Domeniconi \& Box 2004). However, female callitrichids are typically also more food-motivated, whereas males are more vigilant than females (Koenig 1998). Accordingly, males are less interested in participating in experimental tasks and more easily emotionally aroused during testing. But if male performance is controlled for the presence of attention to the test stimuli, their performance is no longer inferior to that of females (Schubiger, Wüstholz, Wunder \& Burkart 2015). The sexes thus do not differ in cognitive ability, but in their motivation to participate in experimental tasks.

The problem that we may never be sure if species differences in cognitive performance are the results of differences in cognitive ability or differences in contextual variables (Macphail 1982) remains an ongoing challenge for any species comparison. Nevertheless, not all tasks are affected by this problem to the same extent. Reversal learning tasks, for instance, are arguably less affected, since individuals first have to reach a criterion of making an initial discrimination. Differences in sensory-motor abilities etc. may well influence how difficult it is for a species to learn a particular discrimination. However, the crucial test is applied only once a specific criterion has been reached, and at least in marmosets, the time needed to achieve this criterion does not predict performance in the reversal trials (Strasser \& Burkart 2012). Furthermore, it is reassuring that the strongest association between a specific task and $G$ in Deaner et al. (2006) was the one between reversal learning and $G$.

A second fundamental methodological issue refers to the task selection and battery development. As to task design, it is increasingly recognized that small differences in methodological details can strongly influence task performance, which has to be taken into account when performing species comparisons. For instance, memory performance strongly depends on task format both in marmosets and squirrel monkeys. Tests of memory often rely on a two-option choice task (e.g. Banerjee et al. 2009), but many individuals are then happy to follow a random choice, which yields a 50\% reward rate. When the choice involves many more options, subjects will be more motivated to remember the location of the food items and provide more accurate estimates of their ability to memorize the location of the food item (Schubiger et al. press). As to battery design, if all tasks in the test battery are drawn from the same 
domain (i.e. a lower-order group factor), rather than from a variety of domains, the positive correlations will reflect a domain-specific ability rather than a more general underlying cognitive factor $(g / G)$. For instance, a positive manifold across a number of maze tasks is consistent with a spatial factor, but not informative with regard to $g$. The issue of task selection is thus closely linked to the identification of domains in animal cognition, which in fact is part of the empirical question that needs to be addressed in intelligence research in animals in general, by using batteries as diverse as possible and statistical procedures that are a priori agnostic to the underlying factor structure.

\subsubsection{False negatives as a result of secondary modularization}

Task selection may also bias the result and potentially produce false negatives if tasks prone to secondary modularization are included. Secondary modularization refers to the process that during ontogeny, individuals may specialize on a specific set of problems in a particular domain (Table 2). Problem solving in this domain becomes automatized and thus acquires many features commonly associated with modules rather than domain-general reasoning, in particular fast and frugal information processing, which is independent of reasoning. Thus, despite the presence of $g$ in a given species, performance among individuals across domains need not be correlated whenever heterogeneous developmental inputs prevail that lead different individuals to specialize in different tasks (Figure 1c). This applies in particular to the small samples typical for nonhuman primate studies.

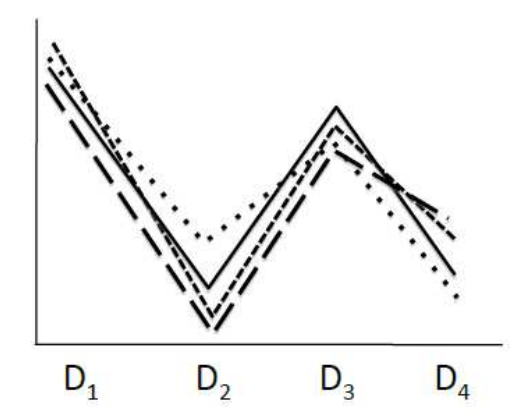

a) domain-specific abilities (largely independent of developmental conditions)

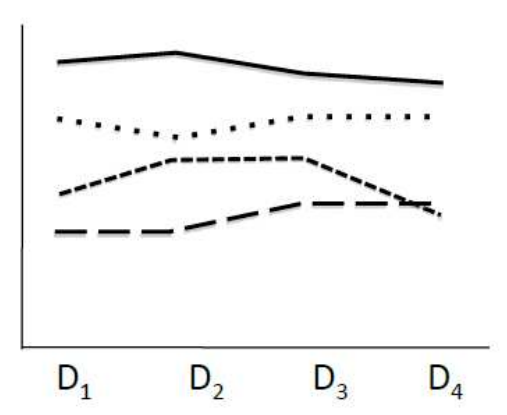

b) domain-general abilities (homogeneous developmental conditions)

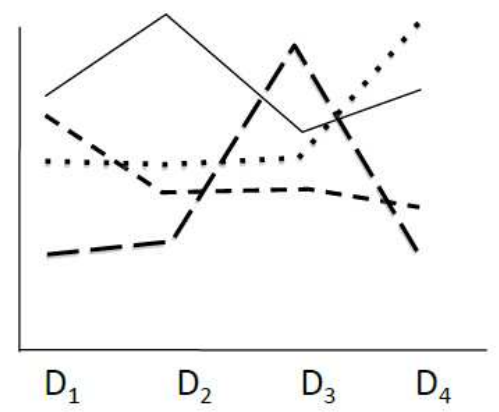

c) domain-general abilities (heterogeneous developmental inputs)

Figure 1: Performance across different cognitive domains $\left(D_{1}-D_{4}\right)$. Each line represents the performance of an individual (or, in highly cultural species, of a population). a) Performance is driven by domain-specific abilities; all individuals perform well in some domains but worse in others, but individual differences across domains are random; b) Performance is driven by domain-general abilities and individuals experience homogenous developmental conditions, which leads to correlated performance between individuals across domains; c) Performance is driven by domain-general abilities but heterogeneous developmental conditions lead to specialization and secondary modularization of individuals in different domains. As a result, performance between individuals across domains is not correlated despite the presence of $g$. 
Prima facie, the situation in Figure 1c may seem incompatible with the positive manifold, which is well documented in humans and perhaps other animals. It is important to keep in mind, however, that psychometric studies in humans are typically performed on subject pools with a rather uniform cultural background (and the same is also true for the rodent studies performed on lab animals with virtually identical rearing conditions). If in human studies, the cultural backgrounds of subjects were more diverse (e.g. ranging from western-industrialized to a variety of hunter-gatherer societies), and only a small number of subjects tested, an outcome as in Figure 1c is quite likely (see also Reyes-Garcia et al. 2016). The notorious difficulty of devising culture-free or at least culture-fair intelligence tests is a direct consequence of this problem (Saklofske et al. 2014).

The prime example for secondary modularization in nonhuman primates is tool use, which is part of many test batteries typically used with nonhuman primates (e.g. Herrmann et al. 2007; Reader et al. 2011). Nonhuman primates vary considerably with regard to tool use, with great apes typically outperforming monkeys. But differences also occur within a species, both between wild and captive animals and among wild populations. Individuals of the same species show much higher propensities to use tools in captivity compared to their counterparts in the wild (Meulman, Sanz, Visalberghi \& van Schaik 2012; van Schaik, Deaner \& Merrill 1999). Once proficient, individuals show tool use with high degrees of automatization and efficiency. Wild populations too vary significantly with regard to their propensity to use tools and solve tool-related problems (e.g. in chimpanzees: Gruber et al. 2011, orangutans: van Schaik et al. 2003, or capuchin monkeys: Cardoso 2013), arguably because they have ontogenetically acquired systematically different affordances of sticks or stones, which are perceived as potential tools in habitual tool users but not in non-tool users.

False negatives resulting from situations as depicted in Figure 1c can be minimized if subjects with comparable rearing conditions are selected, but also if tasks prone to secondary modularization are excluded from test batteries. Thus, instead of naturalistic tasks that test for ontogenetically constructed skills that are likely to become automatized, such as tool use, or the ability to point and understand pointing, or even to use human language systems (Savage-Rumbaugh, Fields, Segerdahl \& Rumbaugh 2005), it is preferable to include tasks testing for more elementary cognitive abilities, such as reversal learning, mental rotation, or quantity discrimination. Likewise, tests should avoid reliance on experience and knowledge of affordances that may differ among individuals depending on their biographies.

Although it is important to identify tasks and abilities prone to secondary modularization, it is not always easy to identify them. One way to do so is to examine the ontogeny of skills that are suspected to be the result of secondary modularization. Such skills should be acquired by developing immatures after a period of learning (perhaps following alternating series of instances of social learning and practice: Meulman, Seed \& Mann 2013; Schuppli et al. in press), and could also potentially show high variation 
among adults. The increasing evidence for a major amount of skill learning by immature primates (e.g. Schuppli et al. in press) and mammals and birds more generally (van Schaik, Burkart, Damerius, Forss, van Noordwijk \& Schuppli 2016) suggests a greater prevalence of secondary modularization in nonhumans than revealed by the size of cultural repertoires (Whiten \& van Schaik 2007). Because in wild populations, social and ecological problems tend to be very uniform for all individuals, variation of skill profiles (Figure 1) between populations (that live under similar, wild or captive, conditions), rather than among individuals of the same population, provides an additional heuristic tool to distinguish between genuine primary and secondary modularity. This criterion would work for primate tool use, for instance. Most powerful to disentangle primary from secondary modularity, finally, are cross-fostering experiments. When cross-fostered individuals exhibit species-typical behavior from the foster species rather than their own species, these behaviors clearly cannot result from primary modules. If the same procedure works within a species at the level of populations, it is similarly evidence for secondary, and thus learned, modules.

\subsection{Psychometric or general intelligence? Future directions for animal studies}

A crucial question that remains unanswered so far is to what extent a reliably identified $g / G$ actually captures general intelligence in a broad sense, i.e. reasoning ability and behavioral flexibility (Gottfredson 1997; Byrne 1994; Rumbaugh \&Washburn 2003; Yoerg 2001; see also section 1.1). If it indeed does so, the processes underlying general intelligence (see also 1.1.2 and 1.2.3) in animals should be broadly similar to those found in humans, with the obvious exception of language, and general intelligence should be correlated with independent measures of reasoning ability and behavioral flexibility (see also Bailey, McDaniel and Thomas 2007). If it is not, the statistically derived psychometric factors may reflect cumulative modularity, i.e. the coexistence of separate, but coevolved modules.

These two possibilities can be teased apart empirically: If $\mathrm{g} / \mathrm{G}$ represents intelligence in a broad sense, it must be possible to independently assess its validity. In principle, an association at a higher hierarchical level (e.g. between-species G) may be absent within the subgroups comprising it (e.g. withinspecies g), a phenomenon known as Simpson's paradox (Kievit, Frankenhuis, Waldorp \& Borsboom 2013). In the present case, we may thus find a correlation between $G$ and EFs but not between $g$ and EFs, which would suggest that $g$ and $G$ were not aspects of the same phenomenon, i.e. general intelligence. Thus, to ensure that $g$ and $G$ are related to the same phenomenon, one must validate both of them independently.

Intraspecific studies of primates have so far largely neglected the approach to validate $g$, but it has provided fruitful insights in rodent studies. In rodents, individual levels of $g$ have been shown to correlate with executive functions such as working memory. Matzel and co-workers have compared 
performance on standardized test batteries that reliably quantify $g$ in mice with several measures of working memory, including short-term memory duration (how long can the mouse remember which arms of a maze it has already visited?), simple memory span (how many symbols associated with food can the mouse remember?), and selective attention (an adapted version of the STROOP task, where the subject has to focus on one dimension of the task while suppressing a second dimension that provides conflicting information). As in human studies, they found that $g$ was most strongly correlated with selective attention, followed by simple memory span and only weakly with short-term memory duration (Matzel et al. 2008, Kolata et al. 2007, 2011; Matzel, Wass \& Kolata 2011). Moreover, they showed that training working memory capacity, but not simple working memory span, promotes selective attention and $g$ (Light et al. 2010). Future validation tests could also examine the correlation between $g$ and conduction speed or the ability to ignore irrelevant, distracting information, which are known correlates of $g$ in humans (Sheppard \& Vernon 2008; Melnick et al. 2013).

The corresponding validation of psychometrically derived $g$-scores in other species, particularly in nonhuman primates, would be highly desirable. Nonetheless, some evidence consistent with $g$ representing domain-general cognitive mechanisms is already available from nonhuman primates. Within chimpanzees, heritability was strongest for overall cognitive performance $g$ rather than for distinct aptitudes (Hopkins, Russell \& Schaeffer 2014), as expected when the latter are due to secondary modularization rather than reflect specific adaptations. As a result, cognitive abilities that load higher on $g$ in chimpanzees are more heritable, phenotypically variable and presumably the result of recent natural selection (Woodley of Menie et al. 2015).

The independent evolution of large numbers of modules instead of general intelligence is particularly difficult to reconcile with interspecific findings of $G$. If we are dealing with independent modules, each species would be expected to possess a different repertoire of primary modules, according to the specific adaptive problems it faces. Importantly, across species, this should not result in a stable $G$ factor. Studies providing evidence for $G$, however, suggest that particular species generally perform better or more poorly across all tested domains. This is also consistent with the empirical findings suggesting that differences in cognitive abilities among primates are concentrated on $G$ (Fernandes et al. 2014). Furthermore, since specific skills, even if complex, can be performed with a very modest amount of brain tissue (e.g. Chittka \& Niven, 2009; Holekamp et al. 2015; Patton \& Braithwaite, 2015), one would not necessarily expect that $G$ as a reflection of a large number of dedicated modules would correlate with brain size. The well-documented positive correlations between $G$ and brain size thus further suggests that $G$ reflects general intelligence, as does the finding that across primate species $G$ was the principal locus of selection in the macroevolution of intelligence (Fernandes et al. 2014). 
Empirical data also support a link between inter-specific $G$ and executive functions: across primate species, brain size is not only correlated with $G$, but also with self (inhibitory) control (MacLean et al. 2014). Figure 2 shows that in addition, this measure of self-control is directly correlated with $G$ as established by Deaner et al. (2006), which has been derived from a completely independent data set.

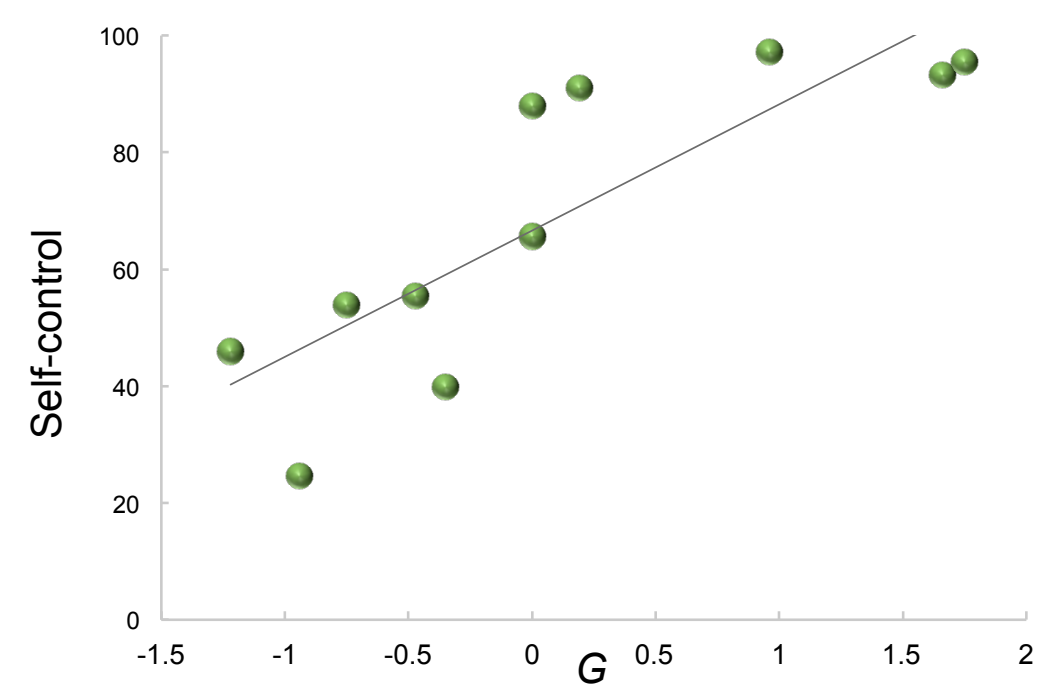

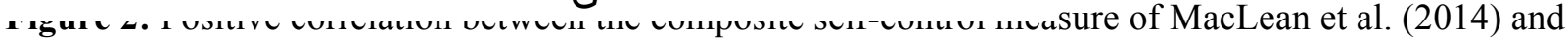
$G$ (Deaner et al. 2006). Adjusted $\mathrm{r}^{2}=0.66, \mathrm{~F}_{(1,9)}=20.75, \mathrm{p}=0.001$ based on PGLS (phylogenetic generalized least squares) analyses. The same results are also found when the inhibitory control tasks included in the composite measure are analyzed separately (Cylinder task: Adjusted $\mathrm{r}^{2}=0.58, \mathrm{~F}_{(1,11)}=20.75, \mathrm{p}=0.002$; Anot-B error: Adjusted $\left.\mathrm{r}^{2}=0.41, \mathrm{~F}_{(1,12)}=10.03, \mathrm{p}=0.008\right)$.

A particularly powerful, but likewise underexplored approach to construct validation consists in training individuals to solve a task in one domain and test to what extent they are able to apply their solution in a different domain. Intraspecific variation in this kind of cognitive flexibility (which is consistent with broad notions of general intelligence as applied by comparative scientists) should be correlated with psychometrically derived measures of individual $g$. Such a pattern would confirm that $g$ is indeed a proxy of animal intelligence broadly defined.

Equally promising is to focus on unusually difficult problems relative to individual performance (i.e. problems that cannot be solved in a routine way) across different cognitive domains and to assess whether to solve them, individuals recruit the same basic cognitive processes that are also strongly correlated with $g$, such as selective attention, or working memory capacity (Geary, 2009; Matzel, Sauce, \& Wass, 2013).

Finally, particularly rigorous validation would be based on extra-domain assays. Just as human $g$ correlates with academic success, workplace success, health and even happiness (for references, see above), one could in principle ask whether $g$ in animals is correlated with outcomes such as the size of cultural repertoires in nature, the ability to rise in social dominance, or to find food during periods of 
scarcity, and thus survival and even fitness. Unfortunately, this approach is difficult to achieve because it requires both reliably quantifying $g$ and the various real life outcomes in animals under natural conditions. More importantly, $g$ may not necessarily predict basic fitness measures such as reproductive success, because of possible tradeoffs between investment into improving general intelligence and other vital activities, such as vigilance or social monitoring.

Table 7 summarizes the issues discussed above in the form of criteria that may be fruitful to guide future studies.

Table 7: Criteria that may be useful in guiding future efforts to (a) reliably identify $g / \mathrm{G}$ in nonhuman animals and (b) evaluate whether a statistically identified $\mathrm{g} / \mathrm{G}$ captures intelligence in a broad sense, i.e. reasoning ability and behavioral flexibility. The last two columns indicate to what extent corresponding criteria have been applied in rodents and primates. See text for details (the relevant sections are indicated in italics)

\begin{tabular}{|l|c|c|}
\hline Criteria for future studies & \multicolumn{2}{|c|}{ already applied in } \\
primates?
\end{tabular}

${ }^{1}$ but not successfully: see Herrmann et al. 2010a; Hopkins et al. 2014; Woodley of Menie et al. 2015.

\section{Implications for the evolution of general intelligence}


Taken together, although more validation remains to be done, especially in primates, the body of evidence is currently more consistent with the presence of domain-general cognitive abilities in primates and mice, reflected in $g$ and $G$, than with the exclusive presence of independent, domain-specific cognitive adaptations. If general intelligence is not limited to humans, this inevitably leads to the question of the conditions favoring the evolution of general intelligence, to which we will turn now. Whereas the evolution of Fodorian, specific, dedicated cognitive adaptations in response to recurrent fitness-relevant problems is seemingly straightforward (but see 1.2.1), the evolution of general intelligence poses a puzzle. Domain-specific cognitive adaptions can be instantiated with modest amounts of neural tissue (Chittka \& Niven 2009; Holekamp et al. 2015; Patton \& Braithwaite 2015) and directly bring about fitness-relevant benefits. Domain-general cognitive ability, however, seems to require substantial amounts of additional expensive brain tissue (Deaner et al. 2007; Reader et al. 2011), and is not automatically linked to fitness-relevant benefits because survival-relevant skills have to be ontogenetically constructed during a process of learning (van Schaik \& Burkart 2011). This ontogenetic construction may be more successful in individuals with higher cognitive ability, as posited by Investment Theory (Cattell 1987), but additional factors also come into play, which renders the link between cognitive ability and fitnessrelevant skills more fragile. For instance, whether a survival-relevant skill is acquired or not may also depend on chance (van Schaik \& Burkart 2011, van Schaik et al. 2016). Furthermore, in order to more reliably translate general cognitive ability into fitness-relevant skills, some mechanisms for adaptive canalizations (as highlighted in section 1.2.2, Table 1) remain necessary, which have to co-evolve or, if already present, be linked to the evolving domain-general cognitive processes. We are therefore faced with the puzzle that domain-general cognitive ability apparently evolved in at least some lineages, or perhaps even in birds and mammals in general, even though its evolution has had to overcome more obstacles compared to the emergence of domain-specific cognitive adaptations. Hence, the goal of this section is to delineate the conditions favoring the evolution of general intelligence.

\subsection{General intelligence as response to domain-specific selection pressures}

The most common approach to explain variation in cognition across species, which has a long and venerable tradition, is to look for specific cognitive challenges in the social or ecological environment and investigate to what extent species facing these challenges have evolved bigger brains (Dunbar \& Shultz 2007a, 2007b; Holekamp et al. 2015; Humphrey 1976; Jolly 1966; Parker 2015; Parker \& Gibson 1977). Comparative analyses, in particular in primates, have shown that brain size is indeed correlated across species with various social and ecological variables, such as social complexity based on bonded relationships (Dunbar 1992; Dunbar \& Shultz 2007b) and tactical deception (Byrne \& Corp 2004), or extractive foraging (Parker 2015), manipulative complexity (Heldstab, Kosonen, Koski, Burkart, van 
Schaik \& Isler 2016) and perceived seasonality (van Woerden, Schaik \& Isler 2014; van Woerden, van Schaik \& Isler 2010; van Woerden, Willems, van Schaik \& Isler 2012). Shultz and Dunbar (2006) present similar analyses for ungulates, with similar conclusions.

Nonetheless, much variation in brain size across species remains unexplained by domain-specific pressures (Holekamp 2007; van Schaik et al. 2012). Furthermore, not all species that excel in sociocognitive tasks, most likely because of their complex social environment, also excel in non-social tasks and evolve big brains. Socio-cognitive abilities in hyenas, for instance, are on a par with those of the larger anthropoid primates, but there is no evidence that like in primates, this would be correlated with particularly powerful cognitive abilities outside this domain (Holekamp 2015). Likewise, callitrichid monkeys outperform their sister lineage, capuchin and squirrel monkeys, in socio-cognitive abilities, but the latter have superior physical cognition (Burkart \& van Schaik 2010; Burkart \& van Schaik 2016). For additional examples of how specific sophisticated cognitive skills can be achieved with very small brains see Chittka and Niven (2009) for insects, or Patton and Braithwite (2015) for fish.

The crucial question thus is: Under what conditions do specific cognitive challenges result in an increase in general intelligence (and thus brain size) rather than in domain-specific cognitive solutions that do not require large amounts of brain tissue and do not translate into benefits in other domains too?

\subsection{Direct selection on general intelligence}

Some have argued that general cognitive ability is not the result of a domain-specific challenge but that it was directly selected for so as to help animals cope with novel or unpredictable environments and overcome unusual or complex ecological challenges. According to this cognitive buffer hypothesis, large brains facilitate the construction of novel behavioral patterns through domain-general cognitive processes such as innovation and learning (Lefebvre, Reader \& Sol 2013; Sol 2009). In support of this hypothesis, more innovative species tend to indeed have bigger brains in birds (Lefebvre, Whittle, Lascaris, \& Finkelstein 1997) and primates (Reader \& Laland 2002), and innovation rates in the wild are correlated with $G$ across primate species (Reader et al. 2011). Furthermore, innovation rates and brain size, and thus presumably $G$, predict colonization success in birds (Sol et al. 2005), mammals (Sol, Bacher, Reader \& Lefebvre 2008), amphibians and reptiles (Amiel, Tingley \& Shine 2011), and fishes (Shumway 2008; but see Drake 2007). Furthermore, large-brained birds use more successful learned strategies to avoid collision with human vehicles on roads (Husby \& Husby 2014). Finally, anthropoid primates (but not lemurs, rodents and omnivorous carnivores) cognitively buffer environmental seasonality (S. Graber et al. in prep.; van Woerden et al. 2014). Taken together, this work convincingly demonstrates that big brains are associated with greater behavioral flexibility and higher innovation rates 
under naturalistic settings, and that these in turn can be beneficial for a range of species when they face novel and unpredictable environments.

What remains to be answered in light of these obvious benefits, then, is why not all species evolved bigger and more powerful brains. It is self-evident that all extant species are clearly smart enough for their current niche, but it is equally evident that a slightly better understanding that traces of a predator actually mark its presence, a better memory for which food sources already have been visited, or better object permanence to better keep track of a disappearing prey would convey a fitness benefit relative to conspecifics. We suggest that it is unlikely that focusing exclusively on potential benefits resulting from gains in brain size will further advance our understanding of the conditions under which domain-specific pressures lead to increased general intelligence. Rather, answering this question requires a focus not only on the benefits, but also on the costs of evolving a bigger brain.

\subsection{Who can afford to evolve general intelligence? Cultural Intelligence}

Some species have larger brains than others which, at least in primates, is associated with higher $G$. Why did these species respond to domain-specific selection pressures with an increase in general intelligence (see also 3.1), or cope with environmental unpredictability by increasing their brain and intelligence, rather than opting for alternative, domain-specific adaptations (see also 3.2)?

To answer these questions, it is important to keep in mind that the conditions under which large brains can evolve are to a substantial degree restricted by their costs (Isler \& van Schaik 2014). Brains are energy-hungry organs that consume a large proportion of the energy available to an organism, in particular in growing immatures (Kuzawa et al. 2014). Thus, natural selection more readily favors an increase in brain size when this leads to an increase in net energy intake, a reduction in its variance, or ideally both. Furthermore, a big brain slows down the organism's development, which means that a species' ability to slow down its life history by increased survival is a fundamental precondition for its opportunity to evolve larger brain size. The latter is only possible for species who are not subject to unavoidable extrinsic mortality, such as high predation pressure: the life-history filter (van Schaik et al. 2012). Isler \& van Schaik (2014) have shown that such a cost perspective can explain a substantial amount of variation in brain size across primates, and that allomaternal care plays an important role in accommodating the costs associated with bigger brains (in particular because food subsidies by allomothers help paying for the energetic costs of the growing immatures, and because of life history consequences; see also Burkart, in press).

Natural selection thus evaluates the net fitness benefit of a bigger brain, which also takes the costs into account. The balance of benefits and costs is critically influenced by how efficiently an individual can translate brain tissue (or general cognitive potential) into survival-increasing innovations, i.e. 
knowledge and skills. The cultural intelligence approach stresses that species that rely more systematically on social learning are more efficient in ontogenetically constructing survival-relevant skills (Herrmann et al. 2007; van Schaik \& Burkart 2011; van Schaik et al. 2012; Whiten \& van Schaik 2007), because social influences are very powerful domain-general canalization processes, as highlighted in Table 1. Whereas in the human literature, many approaches stress the importance of social inputs in the development of intelligence (e.g. Tomasello 1999, Moll \& Tomasello 2007), the evolutionary version of this approach that suggest that social learning also plays a crucial role for the evolution of intelligence and brain size has received far less attention. Importantly, it builds on a broad notion of social learning (Heyes 1994, Box 1984, see also van Schaik, Graber, Schuppli and Burkart in rev for a classification of social learning particularly suitable to test the predictions of the evolutionary dimension of the cultural intelligence hypothesis).

Consistent with the cultural intelligence approach, empirical results show that innovation rates in birds and primates are not only correlated with brain size or $G$, but also with the efficiency of social learning (Reader 2003; Reader et al. 2011). According to the cultural intelligence hypothesis, this is the case because, for species engaging systematically in social learning additional brain tissue translates more reliably in survival-relevant skills, which lowers the threshold for evolution to favor an increase in brain size and general cognitive ability compared with species that do not rely on social learning. The frequency of opportunities for social learning is thus part of the answer why some lineages did evolve bigger brains, whereas others did not, even though they would all benefit from being more intelligent (van Schaik \& Burkart 2011). Put in other words, we can use the pattern of solutions to the canalization problem outlined in Table 1 to better understand under what conditions a species responds to a domainspecific selection pressure with a domain-general adaptation rather than with a narrow, domain-specific modular adaptation. The core message of Table 1 was that all identified canalization problems can readily be overcome by social learning, and therefore, species able to rely more on social learning should be more likely to be able to evolve domain-general cognitive adaptations. In sum, the cultural intelligence approach seems to best accommodate the findings of general intelligence reviewed above. For a more detailed comparison and discussion of the different approaches, see van Schaik, Isler \& Burkart (2012) and Burkart (in press).

The cultural intelligence hypothesis was originally developed to explain why humans have evolved far bigger brains and far greater intelligence than other great apes. Tomasello (1999; see also Herrmann et al., 2007) stressed that humans have evolved of a set of species-specific socio-cognitive skills that facilitate social transmission, by allowing us to participate and exchange knowledge in cultural groups from an early age on. In other words, humans have become specialized in making use of social inputs to ontogenetically construct their skills, and rather than having evolved predominantly into a 
“cognitive niche" (Pinker 2010), they have evolved into a "cultural niche" (Boyd, Richerson \& Henrich 2011). Our extreme dependence on socially guided ontogenetic construction of skills can also explain why the intraspecific link between $g$ and brain size within humans is relatively weak (Pietschnig et al. 2015; Muthukrishna \& Henrich 2016).

Humans can thus be seen as a special case of cultural intelligence, due to the active involvement of caretakers and the improved imitative abilities of our species. This view is consistent with approaches to human cognitive evolution that stress the role of allomaternal care, which not only results in energy subsidies to growing immatures, but also increases the scope of social learning through the availability of more, and more tolerant role models, who eventually also engage in teaching (Burkart, Hrdy, \& van Schaik 2009; Hrdy 2009; Isler \& van Schaik 2014; Burkart \& van Schaik 2016; Kline 2015).

\section{Discussion}

\subsection{Preliminary synthesis}

The current body of evidence reviewed above is arguably most consistent with general intelligence not being unique to humans but also present in other species, even though much validation remains to be done, as outlined in section 2.4 and 2.5. At present, the best-supported model for both animals and humans therefore views the ecological and social cognitive skills that can be measured in a species as the result of two pathways, as indicated in Figure 3. 


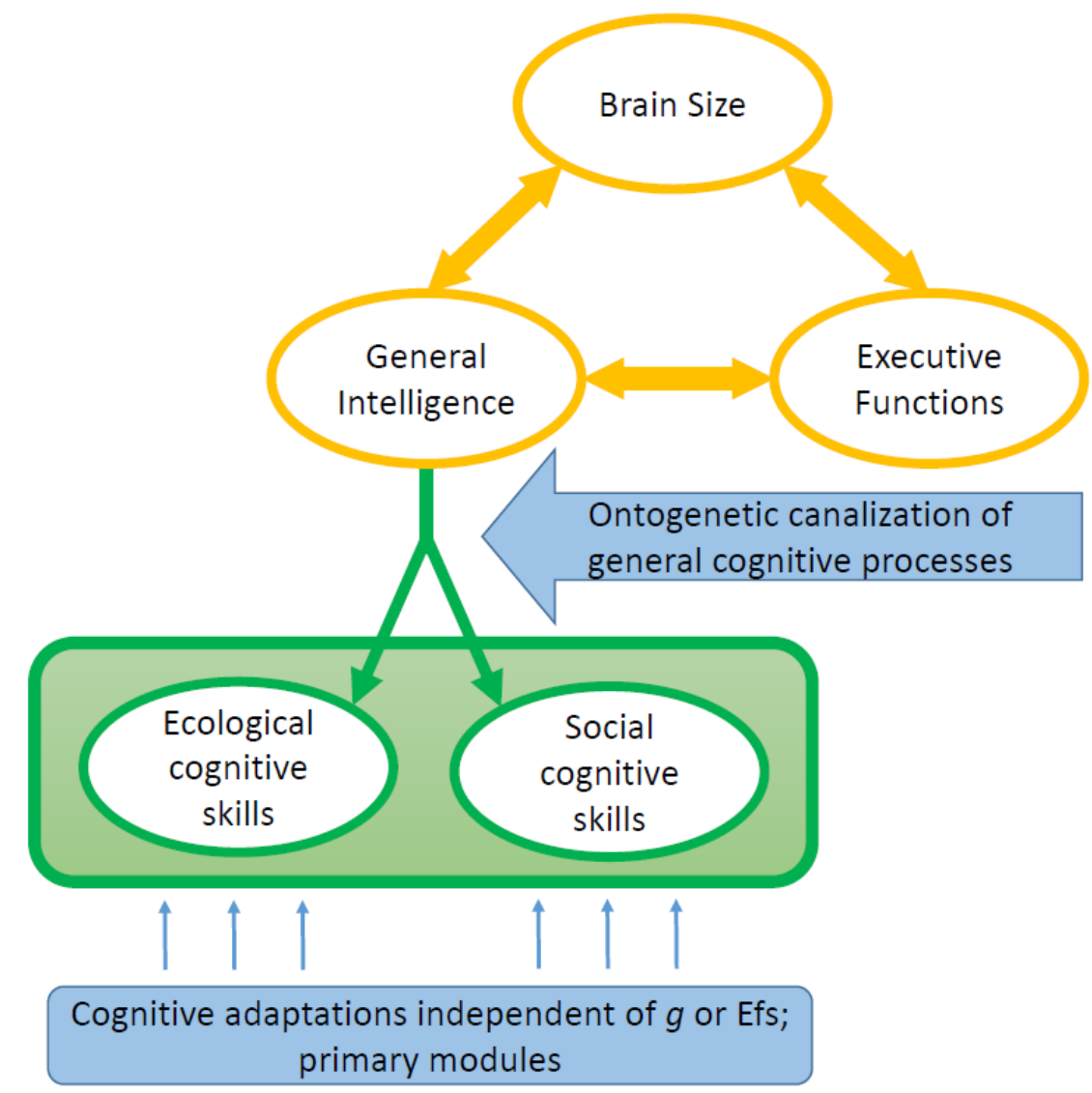

Figure 3: The origin of cognitive skills. Green: Ecological and social cognitive skills that can be measured in animals and that are visible to natural selection because they can result in fitness benefits. Yellow: Empirical interrelations between brain size, general intelligence, and executive functions. The latter two entities are only visible to selection to the extent that they are translated into fitness-enhancing cognitive skills. Blue: Adaptive canalizations that either guide the ontogenetic construction of cognitive skills from general intelligence (see Table 1 for details) or represent fully-fledged Fodorian, modular adaptations that are independent of the domain-general (yellow) nexus.

In the downward pathway, cognitive skills result from general intelligence, which shows strong empirical correlations with brain size and executive functions. These skills correspond to Cattell's crystallized intelligence (Cattell 1963) and Geary's secondary learning (Geary 2005). In this case, the cognitive skills are ontogenetically constructed, facilitated by mechanisms of adaptive canalization beyond Fodorian modularity (summarized in Table 1) and eventually may become automatized (secondary modularization, which makes these skills particularly difficult to identify). As stressed by the cultural intelligence approach, social learning is a particularly efficient mechanism of ontogenetic canalization, in particular in large-brained animals. In the upward pathway, cognitive skills directly emerge as a result of dedicated, Fodorian cognitive modules independent from general intelligence, executive functions (Firestone \& Scholl 2015) or brain size.

These two pathways to cognitive skills can coexist, and in fact almost certainly do. This has major implications. First, closely related, big-brained species that rely to some significant extent on the 
downward pathway and thus general intelligence may nevertheless exhibit rather distinct social and ecological skill sets. Some of their species-specific ontogenetic canalization mechanisms can result in species differences in performance in specific domains, such as extractive foraging and tool use. Second, species may not primarily vary with regard to whether they have $g$ or not, but with regard to the relative importance of these two pathways in building their skill sets, consistent with the increasing evidence for $g$ in several nonhuman species. Approaches like cultural intelligence and the expensive brain framework delineate the conditions under which one or the other is more likely to evolve. This model is thus consistent with the broad pattern of results summarized in this review, including the results of mixedspecies studies (section 2.3), and also with the idea of evolutionary continuity.

This preliminary synthesis suggests there is an alternative way of estimating the importance of general intelligence in a given species. Rather than exclusively relying on comparing the percentage of variance in performance explained by $g$ (which in fact may be misleading, under the conditions outlined in section 2.4.1), one may attempt to estimate the importance of one pathway over the other in constructing an individual's skill set. To do so, it is crucial to be able to distinguish the origin of the skills in the green box, whether they result from the upward or the downward pathway. This is particularly difficult because eventually, skills constructed via the upper pathway may become automatized, and thus difficult to distinguish from primary modules (see also Table 2 in section 1.2.3). To identify them, one needs to show that they critically rely on EFs (see also Table 6b) and show signs of being effortfully learned (see also Meulman et al. 2013; Schuppli et al. in press). This is most feasible when the learning is social, either by directly recording the socially induced patterns of attention and practice (e.g. Jaeggi et al. 2010) or by interspecific cross-fostering (see section 2.4.3) where this is feasible. This alternative way of estimating the importance of general intelligence in a given species may turn out to be a promising complement to the alternatives pursued in nonhuman intelligence research so far.

\subsection{Conclusions}

Overall, the body of evidence from comparative studies lends increasing support to the notion that general intelligence is not unique to humans but also present in nonhuman animals and thus was not as tied up with language as some have suggested. Intra-specific evidence for $g$ is particularly strong in rodents, whereas inter-specific evidence $(G)$ finds most support from primate and bird studies. Nevertheless, the rather young field of research into animal general intelligence still needs to mature just like work on human intelligence took decades to mature.

This enterprise can obviously profit from better integrating knowledge accumulated in the longstanding tradition of human psychometrics, not only with respect to the methodological aspects highlighted above, but also to conceptual issues. For instance, obvious parallels exist between Investment 
Theory (Cattell 1987) and cultural intelligence approaches; pursuing them further may lead to novel insights. In other domains, however, superficial similarities are misleading. Modern massive modularity, for instance, based on very broad notions of modularity and inspired by evolutionary biology (Barrett 2015), hardly informs the debate about whether general intelligence exists in nonhuman animals or not. Among nonhuman animals, the ancestral state most likely corresponds to animal minds being made up entirely of dedicated modular adaptations (Shettleworth 2012). Among extant species, the question is, which behaviors are (still) regulated this way?

It is worth emphasizing that fruitful inputs can flow in the other direction too. For instance, the availability of valid animal models of general intelligence increasingly allows studying the underlying neurobiological and genetic mechanisms in ways that would not be possible in human studies (reviewed in Matzel et al. 2013; Plomin 2001; Galsworthy et al. 2014). Furthermore, via animal studies we can experimentally address the role of factors such as exploration tendency, known to be linked to $g$ in mice (Grossman et al. 2007; Light et al. 2008), most likely via mechanisms stressed by Investment Theory (Cattell 1987). Finally, comparative studies are indispensable in addressing the broader question of where, why and how $g$ evolved. Among the most promising evolutionary explanations for general intelligence is the cultural intelligence approach, which predicts the co-evolution of social learning and general intelligence. This perspective is strongly supported by interspecific studies where social learning but also other social abilities such as deception are strongly correlated with $G$ across species (e.g. Reader et al. 2011) and where brain size is linked to opportunities for social learning during development (van Schaik et al. 2012).

A final issue concerns both animal and human studies. In most intraspecific studies, sociocognitive tasks were not part of the test battery, but where they were, the results were inconclusive. Thus, whereas Hopkins et al. (2014; Woodley of Menie et al. 2015) found socio-cognitive abilities loading on $g$ in chimpanzees, Herrmann et al. (2010a) did not, neither in chimpanzees nor children. This may be because the intraspecific measures of socio-cognitive abilities used so far are less suitable than interspecific ones, for instance because they sometimes produce ceiling or floor effects. However, human test batteries typically also do not include social cognition, and the relationship between general intelligence and socio-cognitive abilities in humans therefore remains poorly understood (Korman et al. 2015). Investigating the link between socio-cognitive abilities and general intelligence within humans thus is an important research priority.

\section{Acknowledgements}


We would like to thank Sonja Koski and Kay Holekamp for discussion, Sandra Heldstab for performing the PGLS analyses for Figure 2, and Jonathan Evans, Barbara Finlay, David Geary, Willem Frankenhuis, as well as the anonymous reviewers for their valuable and very constructive feedback. This work was supported by Swiss National Funds projects 310030_13083 and 310030B_160363/1 and the A. H. Schultz-Stiftung. 
Table 3: Intra-specific studies that have assessed and analyzed correlated performance across at least three cognitive tasks within subjects of the same species, for rodents, primates, and other species

\begin{tabular}{|c|c|c|c|c|}
\hline & Species (n) & Test battery & Key findings and conclusion & Reference \\
\hline \multirow{6}{*}{ 苞 } & Rats $\left(22+20^{1}\right)$ & $\begin{array}{l}4 \text { tasks: attention to novelty, speed and } \\
\text { accuracy of reasoning ( } 8 \text {-arm radial maze), } \\
\text { response flexibility (detour problem) }\end{array}$ & $\begin{array}{l}\text { Evidence for } g \text { in both samples; } g \text { is correlated with brain } \\
\text { weight (second sample) }\end{array}$ & Anderson, 1993 \\
\hline & $\begin{array}{l}\text { Mice } \\
\text { (two strains: } 34 \\
+41 \text { ) }\end{array}$ & $\begin{array}{l}5 \text { water escape tasks: route learning (Hebb- } \\
\text { Williams maze), use of spatial navigational } \\
\text { cues (Morris water maze), spatial reversal } \\
\text { learning and visual reversal learning (T maze), } \\
\text { place learning (four arm maze); } \\
\text { plus activity control task }\end{array}$ & $\begin{array}{l}\text { Evidence for } g \text { in both strains (explaining } 61 \% \text { and } 55 \% \text { of } \\
\text { variance in the latency measures, and } 28 \% \text { and } 37 \% \text { in the } \\
\text { error measures); authors stress limited implication for } g \\
\text { because mainly spatial tasks; activity loads on first factor in } \\
\text { strain A but not in strain B }\end{array}$ & $\begin{array}{l}\text { Locurto \& } \\
\text { Scanlon, } 1998\end{array}$ \\
\hline & Mice (40) & $\begin{array}{l}6 \text { tasks: curiosity (spontaneous alternation in } \\
\text { T-maze), route learning (Hebb-Williams } \\
\text { maze), use of spatial navigational cues (Morris } \\
\text { water maze), detour problem (burrowing task), } \\
\text { contextual memory, plug puzzle; } \\
\text { plus anxiety in new environments (open field) }\end{array}$ & $\begin{array}{l}\text { Evidence for } g \text { (explaining } 31 \% \text { of variance); } g \text { is } \\
\text { independent of anxiety }\end{array}$ & $\begin{array}{l}\text { Galsworthy et al., } \\
2002\end{array}$ \\
\hline & Mice (60) & $\begin{array}{l}6 \text { tasks: route learning (Hebb-Williams), } \\
\text { place learning (plus maze), and a set of detour } \\
\text { problems; } 3 \text { working memory tasks (eight arm } \\
\text { radial maze, } 4 \times 4 \text { radial maze, visual non- } \\
\text { matching to sample), } \\
\text { plus } 3 \text { activity and stress control tasks }\end{array}$ & $\begin{array}{l}\text { No evidence for } g \text { (first factor explains } 19.4 \% \text { of variance, } \\
\text { control tasks included in PCA) }\end{array}$ & Locurto et al.,2003 \\
\hline & Mice (56) & $\begin{array}{l}\text { Standard mouse battery of } 5 \text { tasks: associative } \\
\text { fear conditioning, operant avoidance, path } \\
\text { integration (Lashley III maze), odor } \\
\text { discrimination, and spatial navigation (Spatial } \\
\text { water maze) } \\
\text { plus open field exploration task }\end{array}$ & $\begin{array}{l}\text { Evidence for } g \text { (explaining } 38 \% \text { of variance); exploration } \\
\text { propensity related to individual learning ability }\end{array}$ & Matzel et al., 2003 \\
\hline & Mice (21) & Variant of standard mouse battery & Evidence for $g$ (explaining $43 \%$ of variance); $g$ covaries & Kolata et al., 2005 \\
\hline
\end{tabular}




\begin{tabular}{|c|c|c|c|}
\hline & $\begin{array}{l}\text { plus exploration task (open field), long term } \\
\text { retention (retest in Lashley III maze after } 30 \\
\text { days) and working memory task (simultaneous } \\
\text { performance in two eight arm radial mazes) }\end{array}$ & $\begin{array}{l}\text { with exploration and working memory capacity but not with } \\
\text { long term retention }\end{array}$ & \\
\hline $\begin{array}{l}\text { Mice ( } 84 \text { unre- } \\
\text { lated }{ }^{1} \text {, and } 167 \\
\text { siblings) }\end{array}$ & $\begin{array}{l}\text { Tasks from Galsworthy et al. } 2002 \\
\text { plus object exploration and } 2^{\text {nd }} \text { problem } \\
\text { solving task }\end{array}$ & $\begin{array}{l}\text { Evidence for } g \text { (explaining } 23 \%-41 \% \text { of variance); } g \\
\text { shows sibling correlations of } 0.17-0.21 \text { and an estimated } \\
\text { heritability of } 40 \% \text { (upper-limit) }\end{array}$ & $\begin{array}{l}\text { Galsworthy et al., } \\
2005\end{array}$ \\
\hline Mice $(47+51)$ & $\begin{array}{l}\text { Exp. 1: } 5 \text { tasks: detour, win-shift, olfactory } \\
\text { discrimination, fear conditioning and operant } \\
\text { acquisition; } \\
\text { plus open field and light-dark control tasks. } \\
\text { Exp. 2: similar but optimized task battery } \\
\text { (same detour and fear conditioning but } 3 \text { new } \\
\text { tasks, including working memory); same } \\
\text { control tasks }\end{array}$ & $\begin{array}{l}\text { Evidence for } g \text { (explaining } 28 \%-34 \% \text { of variance) but only } \\
\text { after removing control procedures from the analysis; } g \text { was } \\
\text { stronger in the second experiment }\end{array}$ & $\begin{array}{l}\text { Locurto et al., } \\
2006\end{array}$ \\
\hline Mice (43) & $\begin{array}{l}\text { Standard mouse battery; } \\
\text { plus } 21 \text { tests of exploratory behavior, } \\
\text { sensory/motor function (e.g. running and } \\
\text { swimming speed, balance tasks, grip strength) } \\
\text { and fitness, emotionality, and hormonal and } \\
\text { behavioral stress reactivity }\end{array}$ & $\begin{array}{l}\text { Evidence for } g \text { (explaining } 32 \% \text { of variance); open field } \\
\text { exploration and } 7 \text { other explorative behaviors also loaded } \\
\text { on this first factor but } g \text { was not correlated with general } \\
\text { activity, sensory/motor function, physical characteristics or } \\
\text { direct measures of fear; lower level biological properties } \\
\text { load weakly and inconsistently on } g\end{array}$ & Matzel et al., 2006 \\
\hline Mice (27) & $\begin{array}{l}\text { Standard mouse battery; } \\
\text { plus selective attention (complex } \\
\text { discrimination), short term memory capacity } \\
\text { (nonspatial radial arm maze), short term } \\
\text { memory duration (delayed reinforced } \\
\text { alternation) }\end{array}$ & $\begin{array}{l}\text { Evidence for } g \text { (explaining } 44 \% \text { of variance); } g \text { is most } \\
\text { strongly correlated with selective attention, followed by } \\
\text { simple memory capacity and only weakly with short-term } \\
\text { memory duration }\end{array}$ & Kolata et al., 2007 \\
\hline $\begin{array}{l}\text { Balb/C Mice } \\
(56)\end{array}$ & $\begin{array}{l}\text { Standard mouse battery } \\
\text { plus working memory span and capacity, and } \\
12 \text { non-cognitive tests of unlearned behaviors } \\
\text { and fitness }\end{array}$ & $\begin{array}{l}\text { Evidence for } g \text { (explaining } 31 \% \text { of variance); old subjects } \\
(19-21 \text { months of age) had lower } g \text { than young ones }(3-5 \\
\text { months of age) but also showed higher variability. Working } \\
\text { memory capacity and duration explained variance in } g \text {, and }\end{array}$ & Matzel et al., 2008 \\
\hline
\end{tabular}




\begin{tabular}{|c|c|c|c|}
\hline & & $\begin{array}{l}\text { particularly so in old mice. Old mice with age-related } \\
\text { cognitive decline had increased body weight and decreased } \\
\text { activity. Some non-cognitive variables are also correlated } \\
\text { with } g \text {. }\end{array}$ & \\
\hline Mice (69) & $\begin{array}{l}\text { Standard mouse battery as adults; } \\
\text { plus extensive exposure to } 12 \text { novel } \\
\text { environments prior to testing }\end{array}$ & $\begin{array}{l}\text { Evidence for } g \text { (explaining } 27 \% \text { of variance); exposure to } \\
\text { novelty as juveniles (from } 39 \text { days of age) and young-adults } \\
\text { (from } 61 \text { days of age) increased exploration but did not } \\
\text { affect } g \text { compared to control groups when tested as adults } \\
\text { (from } 79 \text { days of age) }\end{array}$ & Light et al., 2008 \\
\hline Mice (241) & $\begin{array}{l}\text { Standard mouse battery; subsample of } 78 \\
\text { subjects also tested with } 2 \text { additional spatial } \\
\text { tasks (win-stay and reinforced alternation) }\end{array}$ & $\begin{array}{l}\text { Evidence for } g \text { (explaining } 38 \% \text { of variation); identification } \\
\text { of additional domain-specific factor for tasks that depend on } \\
\text { hippocampal/spatial processing in subsample }\end{array}$ & Kolata et al., 2008 \\
\hline Mice (60) & $\begin{array}{l}\text { Standard mouse battery; } \\
\text { plus prefrontal cortex gene expression profiles }\end{array}$ & $\begin{array}{l}\text { Evidence for } g \text { (explaining } 41-42 \% \text { of variance); } \\
\text { dopaminergic genes plus one vascular gene significantly } \\
\text { correlated with } g \text {; D1-mediated dopamine signaling in the } \\
\text { prefrontal cortex is predictive of } g \text {, arguably through its } \\
\text { modulation of working memory }\end{array}$ & Kolata et al., 2010 \\
\hline Mice (29) & $\begin{array}{l}\text { Standard mouse battery; } \\
\text { plus extensive training on short term memory } \\
\text { duration and working memory capacity and a } \\
\text { selective attention task (Mouse-Stroop) }\end{array}$ & $\begin{array}{l}\text { Evidence for } g \text { (explaining } 30 \% \text { of variance); working } \\
\text { memory training promotes } g \text {, largely but not exclusively via } \\
\text { increased selective attention; effects are smaller when } \\
\text { selective attention load of training task is reduced }\end{array}$ & Light et al., 2010 \\
\hline Mice (42) & $\begin{array}{l}\text { Standard mouse battery: } \\
\text { plus } 2 \text { exploration tasks (open field and novel } \\
\text { environments) }\end{array}$ & $\begin{array}{l}\text { Evidence for } g \text { (explaining } 40 \% \text { of variance); link between } \\
g \text { and exploration propensity is mediated by different rates } \\
\text { of habituation in high vs. low } g \text { subjects }\end{array}$ & $\begin{array}{l}\text { Light et al., } 2011 \text {, } \\
\text { experiment } 2\end{array}$ \\
\hline Mice (26) & $\begin{array}{l}5 \text { tasks: acquisition of three learning tasks } \\
\text { (passive avoidance, shuttle avoidance, } \\
\text { reinforced alternation), reversal learning in } \\
\text { three tasks (shuttle avoidance, reinforced } \\
\text { alternation, water maze) and selective } \\
\text { attention. } \\
\text { plus longitudinal working memory training } \\
\text { (radial arm maze task with overlapping cues, }\end{array}$ & $\begin{array}{l}\text { Evidence for } g \text { (explaining } 26 \%-37 \% \text { of variance); } \\
\text { Longitudinal working memory training prevents age-related } \\
\text { decline of attention, learning abilities and cognitive } \\
\text { flexibility; non-cognitive variables load moderately to } \\
\text { weakly on } g \text { and in a non-consistent manner; } \\
\text { old (from } 18 \text { months of age); young (from } 5 \text { months of age) }\end{array}$ & Matzel et al., 2011 \\
\hline
\end{tabular}




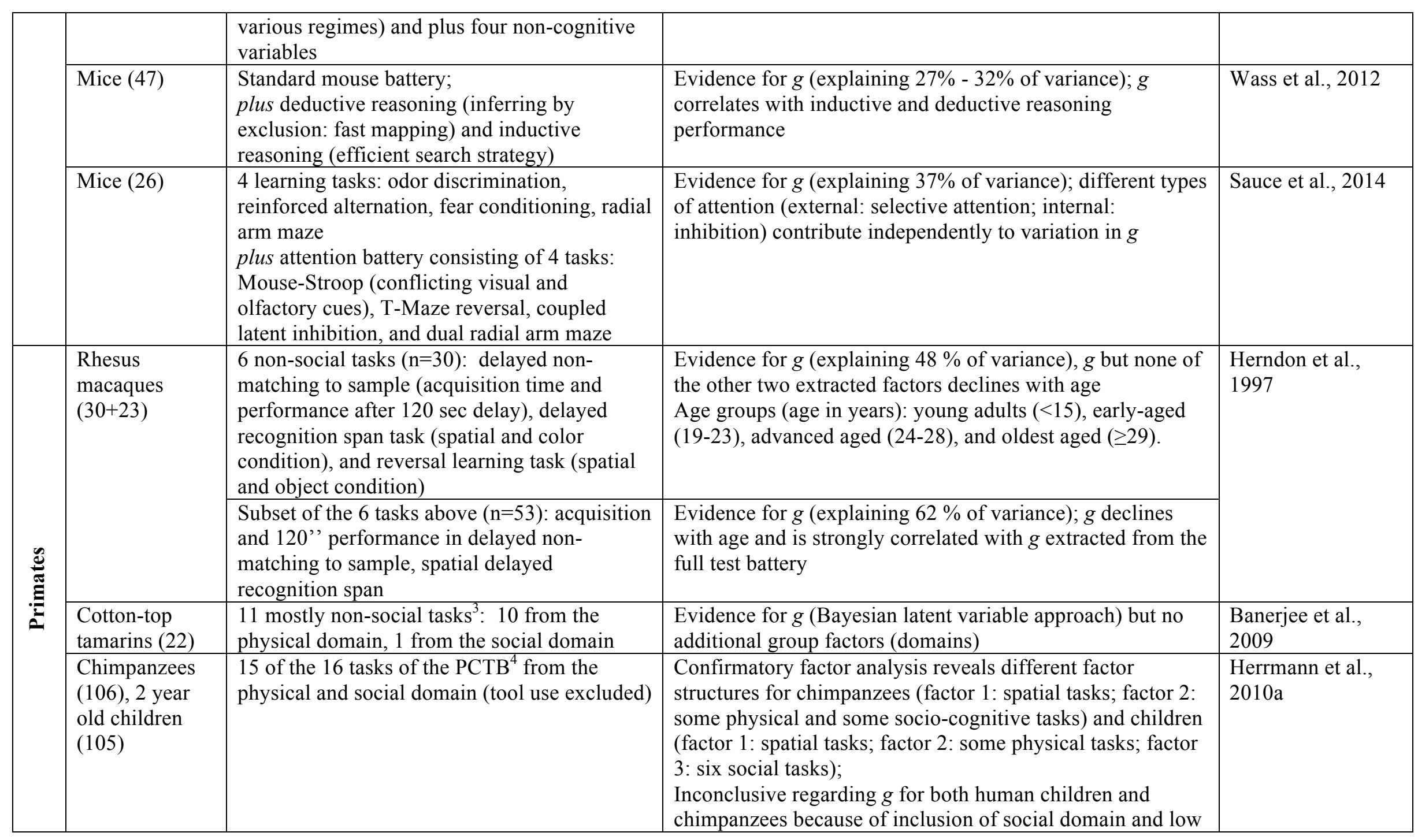




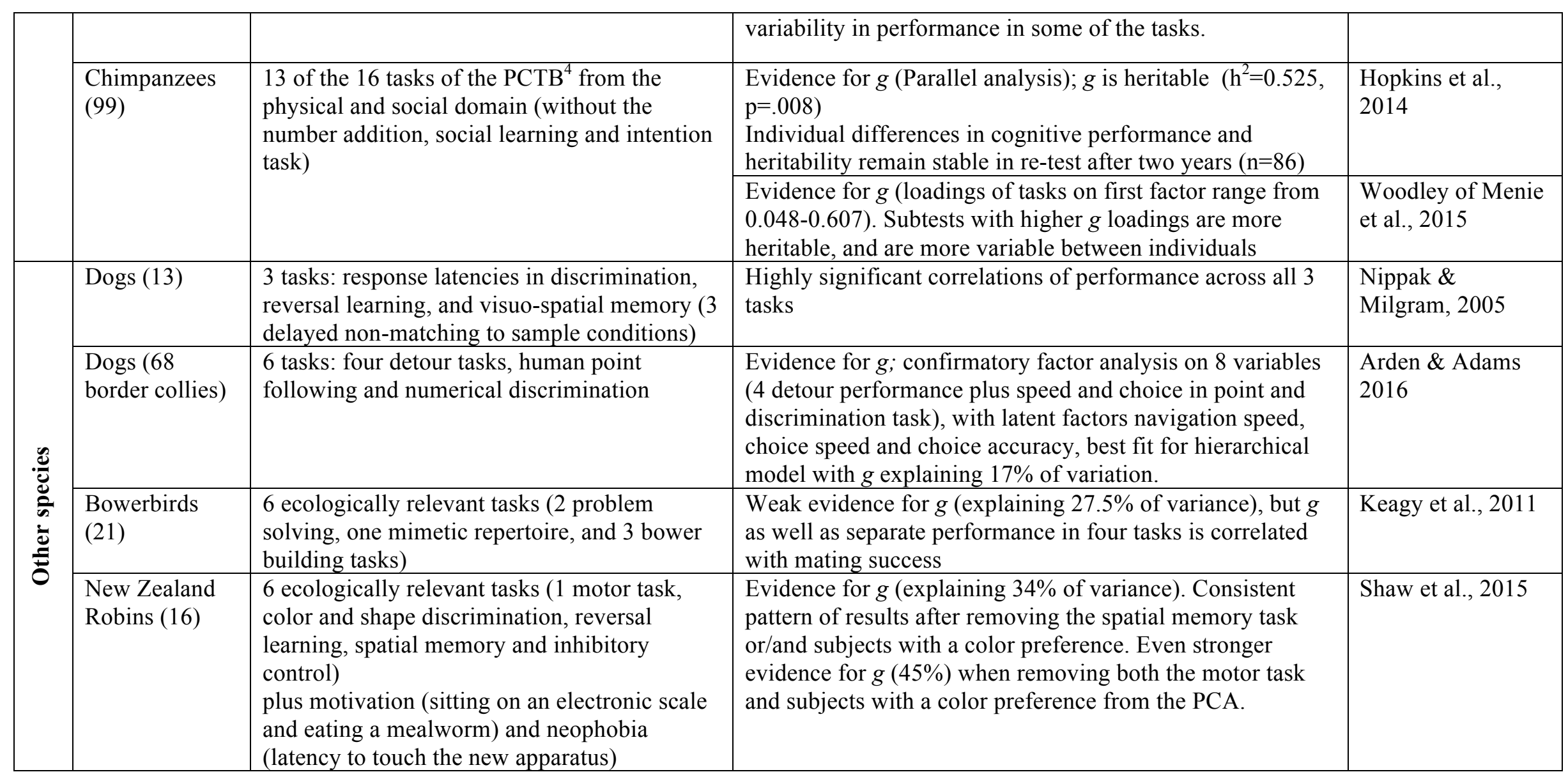

Notes:

${ }^{1}$ In the second sample, variation in brain size was induced by prenatal exposure to methyl-azoxymethanol which induces microcephaly.

${ }^{2}$ Data for 40 subjects was taken from Galsworthy et al. 2002 
${ }^{3}$ Inhibition (occluded reach, A-not-B error, reversal learning), perceptual speed (targeted reach), exploration, numerical discrimination, acoustic discrimination, inspection time (objects and social), memory (hidden reward retrieval), food extraction puzzle

${ }^{4}$ The PCTB (Primate Cognition Test Battery, Herrmann et al. 2007) consists of 16 tasks from the physical domain (space: spatial memory, object permanence, rotation, transposition; quantities: relative numbers, addition numbers; causality: noise, shape, tool use, tool properties) and the social domain (social learning; communication: comprehension, pointing cups, attentional state; Theory of Mind: gaze following, intentions). 
Table 4: Inter-specific, comparative studies that have assessed correlated cognitive performance across species

\begin{tabular}{|c|c|c|c|}
\hline Species (n) & Type of study & Key finding & Reference \\
\hline $\begin{array}{l}\text { Primate species } \\
\text { (116) }\end{array}$ & $\begin{array}{l}\text { Correlation of ecologically relevant cognitive abilities } \\
\text { (innovation, tool use and social learning) and volume } \\
\text { measures of the executive brain (neocortex and striatum) } \\
\text { and brainstem (mesencephalon and medulla oblongata) }\end{array}$ & $\begin{array}{l}\text { The } 3 \text { measures were correlated across non-human } \\
\text { primate species and with both absolute and relative } \\
\text { executive brain volumes; results consistent with } G\end{array}$ & $\begin{array}{l}\text { Reader \& } \\
\text { Laland, } \\
2002\end{array}$ \\
\hline $\begin{array}{l}\text { Primate taxa (24) } \\
\text { (3 great ape } \\
\text { species, } 1 \text { lesser } \\
\text { ape, and } 7 \\
\text { catarrhine, } 6 \\
\text { platyrrhine \& } 7 \\
\text { prosimian genera) }\end{array}$ & $\begin{array}{l}\text { Meta-analysis of } 9 \text { experimental paradigms (detour } \\
\text { problems, patterned-string problems, invisible } \\
\text { displacement, tool use, object discrimination learning set, } \\
\text { reversal learning, oddity learning, sorting, and delayed } \\
\text { response) of captive subjects using hierarchical Bayesian } \\
\text { latent variable analysis (Johnson et al, 2002) }\end{array}$ & $\begin{array}{l}\text { Species- } G \text { explains } 85 \% \text { of variance; great apes } \\
\text { (Gorilla, Pan, Pongo) outperformed all other genera; } G \\
\text { is positively correlated with various measures of brain } \\
\text { size. }\end{array}$ & $\begin{array}{l}\text { Deaner et } \\
\text { al., } 2006 \text {, } \\
2007\end{array}$ \\
\hline $\begin{array}{l}\text { Primate species } \\
\text { (62) (including } \\
\text { apes, catarrhine } \\
\text { and platyrhine } \\
\text { monkeys, \& } \\
\text { prosimians) }\end{array}$ & $\begin{array}{l}\text { Meta-analysis on ecologically relevant tasks: behavioral } \\
\text { innovation, social learning, tool use, extractive foraging } \\
\text { (data from Reader and Laland,2002), and tactical deception } \\
\text { (data from Byrne and Whiten, 1990) using principal } \\
\text { component, factor and phylogenetic analyses }\end{array}$ & $\begin{array}{l}\text { Species- } G \text { explains } 65 \% \text { of the variance in cognitive } \\
\text { performance and covaries with brain size. } G \text { also } \\
\text { covaried with results from captive subjects, i.e. the } \\
\text { species- } G \text { from Deaner et al, } 2006 \text { and learning } \\
\text { performance from Riddel \& Corl, 1977). }\end{array}$ & $\begin{array}{l}\text { Reader et } \\
\text { al., } 2011\end{array}$ \\
\hline $\begin{array}{l}\text { Primate species } \\
\text { (69) } \\
\text { (including apes, } \\
\text { catarrhine and } \\
\text { platyrhine } \\
\text { monkeys, \& } \\
\text { prosimians) }\end{array}$ & $\begin{array}{l}\text { Meta-analysis of data sets from Reader et al. (2011, } \\
\text { innovation, tool use, social learning, and extractive } \\
\text { foraging) and Byrne and Whiten (1990, tactical deception) } \\
\text { using Principal Axis Factor Analysis and Unit Weighted } \\
\text { Factor Analysis }\end{array}$ & $\begin{array}{l}\text { Differences in cognitive abilities among primates are } \\
\text { concentrated on } G \text { (explaining almost } 62 \% \text { of variance) } \\
\text { and this effect is particularly pronounced in catarrhines } \\
\text { (i.e. apes and Old World monkeys) }\end{array}$ & $\begin{array}{l}\text { Fernandes } \\
\text { et al., } 2014\end{array}$ \\
\hline
\end{tabular}


Table 5: Mixed studies that have simultaneously anaylzed correlated performance within and between species

\begin{tabular}{|c|c|c|c|}
\hline Species (n) & Type of study & Key finding & Reference \\
\hline $\begin{array}{l}\text { Chimpanzees } \\
(106) \\
\text { Orangutans (32) } \\
2.5 \text {-year old } \\
\text { human children } \\
(105)\end{array}$ & $\begin{array}{l}\text { Psychometric study using the Primate Cognitive Test } \\
\text { Battery (PCTB) consisting of } 16 \text { tasks from the physical } \\
\text { domain (space: spatial memory, object permanence, } \\
\text { rotation, transposition; quantities: relative numbers, } \\
\text { addition numbers; causality: noise, shape, tool use, tool } \\
\text { properties) and the social domain (social learning; } \\
\text { communication: comprehension, pointing cups, attentional } \\
\text { state; Theory of Mind: gaze following, intentions) using } \\
\text { analysis of variance }\end{array}$ & $\begin{array}{l}\text { Chimpanzees and human children performed equally } \\
\text { well (and better than orangutans) in the physical domain } \\
\text { but the children outperformed both ape species in the } \\
\text { social domain; results not consistent with } G\end{array}$ & $\begin{array}{l}\text { Herrmann } \\
\text { et al., } 2007\end{array}$ \\
\hline $\begin{array}{l}\text { Bonobos, } \\
\text { chimpanzees, } \\
\text { gorillas and } \\
\text { orangutans (23) }\end{array}$ & $\begin{array}{l}8 \text { non-social tasks from various studies: spatial knowledge } \\
\text { (i.e. delayed response, inhibition, A-not-B, rotations, } \\
\text { transpositions and object permanence), tool use ( } 4 \text { tests), } \\
\text { inferential reasoning by exclusion, quantity discrimination, } \\
\text { causal reasoning and color, size and shape discrimination } \\
\text { learning }\end{array}$ & $\begin{array}{l}\text { No evidence for } g \text {; but some individuals perform } \\
\text { consistently well across tasks }\end{array}$ & $\begin{array}{l}\text { Herrmann } \\
\text { \& Call, } \\
2012\end{array}$ \\
\hline $\begin{array}{l}\text { Chimpanzees (19), } \\
\text { orangutans (10), } \\
\text { bonobos (5), } \\
\text { gorillas (8) } \\
\text { long-tailed } \\
\text { macaques (12), } \\
\text { spider monkeys } \\
(18), \\
\text { capuchin monkeys } \\
(27)\end{array}$ & $\begin{array}{l}\text { Re-analysis of data obtained from two psychometric studies } \\
\text { resulting in } 17 \text { tasks from four physical domains (inhibition } \\
\text { from Amici et al. } 2008 \text { and 2010, memory, transposition } \\
\text { and support from Herrmann et al. 2007) with captive } \\
\text { subjects using a hierarchical Bayesian modeling approach }\end{array}$ & $\begin{array}{l}\text { Most variance explained by species and cognitive } \\
\text { domain; results not consistent with } G\end{array}$ & $\begin{array}{l}\text { Amici et } \\
\text { al., } 2012 \text {; } \\
\text { Barney et } \\
\text { al., } 2015\end{array}$ \\
\hline
\end{tabular}




\section{References}

Abutalebi, J., \& Clahsen, H. (2015) Bilingualism, cognition, and aging. Bilingualism: Language and Cognition 18(01):1-2.

Amici, F., Barney, B., Johnson V. E., Call, J., \& Aureli, F. (2012) A modular mind? A test using individual data from seven primate species. PLoS One 7(12):e51918.

Amici, F., Aureli, F., \& Call, J. (2008) Fission-fusion dynamics, behavioral flexibility, and inhibitory control in primates. Current Biology, 18(18):1415-1419.

Amiel, J. J., Tingley, R., \& Shine, R. (2011) Smart moves: effects of relative brain size on establishment success of invasive amphibians and reptiles. PLoS One 6(4):e18277.

Anderson, M. L. \& Finlay, B. L. (2014) Allocationg structure to function: the strong links between neuroplasticity and natural selection. Frontiers in Human Neuroscience, 7, 918, $1-16$.

Anderson, B. (1993) Evidence from the rat for a general factor that underlies cognitive performance and that relates to brain size: intelligence? Neuroscience Letters 153(1):98102.

Aplin, L. M., Farine, D. R., Morand-Ferron, J., Cockburn, A., Thornton, A., \& Sheldon, B. C. (2015) Experimentally induced innovations lead to persistent culture via conformity in wild birds. Nature 518(7540): 538-541.

Arden, R. \& Adams, M.J. (2016) A general intelligence factor in dogs. Intelligence 55: 79-85.

Baddeley, A. (2010). Working memory. Current Biology 20:R136-140.

Bailey, A. M., McDaniel, W. F., \& Thomas, R. K. (2007). Approaches to the study of higher cognitive functions related to creativity in nonhuman animals. Methods, 42(1), 3-11.

Banerjee, K., Chabris, C. F., Johnson, V. E., Lee, J. J., Tsao, F. \& Hauser, M. D. (2009) General intelligence in another primate: individual differences across cognitive task performance in a New World monkey (Saguinus oedipus). PLoS ONE 4(6):e5883.

Barbey, A. K., Colom, R., Solomon, J., Krueger, F., Forbes, C. \& Grafman, J. (2012) An integrative architecture for general intelligence and executive function revealed by lesion mapping. Brain 135(4):1154-1164.

Barney, B. J., Amici, F., Aureli, F., Call, J. \& Johnson, V. E. (2015) Joint Bayesian Modeling of Binomial and Rank data for Primate Cognition. Journal of the American Statistical Association 110(510):573- 582.

Barrett, H. C. (2015) Modularity. In: Evolutionary Perspectives on Social Psychology, eds. V. Zeigler-Hill, L. L. M. Welling \& T. K. Schackelford, New York: Springer International Publishing: 39-51.

Barrett, H. C. \& Kurzban, R. (2006) Modularity in cognition: framing the debate. Psychological Review 113(3):628-647.

Barrett, H. C. \& Kurzban, R. (2012) What are the functions of System 2 modules? A reply to Chiappe and Gardner. Theory \& Psychology 22(5):683-688.

Bartholomew, D. J., Deary, I. J., \& Lawn, M. (2009). A new lease of life for Thomson's bonds model of intelligence. Psychological review, 116(3), 567-579.

Behrens, T. E. J., Hunt, L. T., Woolrich, M. W. \& Rushworth, M. F. S. (2008) Associative learning of social value. Nature 456(7219):245-249.

Bialystok, E., Craik, F. I. \& Luk, G. (2012) Bilingualism: Consequences for mind and brain. Trends in Cognitive Sciences 16(4):240-250.

Bilalić, M., Langner, R., Ulrich, R. \& Grodd, W. (2011) Many faces of expertise: fusiform face area in chess experts and novices. The Journal of Neuroscience 31(28):10206-10214.

Blair, C. (2006) How similar are fluid cognition and general intelligence? A developmental neuroscience perspective on fluid cognition as an aspect of human cognitive ability. Behavioral and Brain Sciences 29:109-160.

Bolhuis, J. J., Brown, G. R., Richardson, R. C., \& Laland, K. N. (2011). Darwin in mind: New opportunities for evolutionary psychology. PLoS Biol, 9(7), e1001109.

Boyd, R., Richerson, P. J., \& Henrich, J. (2011). The cultural niche: Why social learning is essential for human adaptation. Proceedings of the National Academy of Sciences, 108(Supplement 2), 10918-10925. 
Bouchard, T. J. (2014) Genes, evolution and intelligence. Behavioural Genetics 44(6):549-77.

Brodin, A. (2010) The history of scatter hoarding studies. Philosophical Transactions of the Royal Society B: Biological Sciences 365(1542):869-881.

Brown, J., Kaplan, G., Rogers, L. J. \& Vallortigara, G. (2010) Perception of biological motion in common marmosets (Callithrix jacchus): by females only. Animal Cognition 13(3):555-564.

Burgess, G. C., Gray, J. R., Conway, A. R. A. \& Braver, T. S. (2011) Neural mechanisms of interference control underlie the relationship between fluid intelligence and working memory span. Journal of Experimental Psychology: General 140(4):674.

Burkart, J. M. (in press) The evolution and consequences of sociality. In: Oxford Handbook of Comparative Psychology, eds. J. Call, G. M. Burghardt, I. M. Pepperberg, C. T. Snowdon \& T. Zentall.

Burkart, J. M., Hrdy, S. B., \& van Schaik, C. P. (2009) Cooperative breeding and human cognitive evolution. Evolutionary Anthropology 18:175-186.

Burkart, J. M. \& van Schaik, C. P. (2016). Revisiting the consequences of cooperative breeding. A response to Thornton \& McAuliffe (2015). Journal of Zoology, doi: 10.1111/jzo.12322.

Burkart, J. M. \& van Schaik, C. P. (2016) The cooperative breeding perspective helps pinning down when uniquely human evolutionary processes are necessary. Commentary to Richerson et al. (2016). Behavioral and Brain Sciences, 39, e34.

Burkart, J. M. \& van Schaik, C. P. (2010) Cognitive consequences of cooperative breeding. Animal Cognition, 31:1-19.

Byrne, R. W. (1994) The evolution of intelligence. In: Behaviour and Evolution, eds. P. J. B. Slater \& T. R. Halliday. Cambridge University Press.

Byrne, R. W. \& Corp, N. (2004) Neocortex size predicts deception rate in primates. Proceedings of the Royal Society B 271:1693-1699.

Byrne, R.W. \& Whiten A. (1990) Tactical deception in primates: the 1990 database. Primate Report 27:1-101.

Cardoso, R. M. (2013) Resolução de problema por macacos-prego selvagens (Sapajus libidinosus) de duas populações com diferentes repertórios de uso de ferramentas. (PhD), Universidade de São Paulo.

Carey, S. (2009) The Origin of Concepts. Oxford University Press.

Carroll, J. B. (1993) Human cognitive abilities: A survey of factor-analytic studies. Cambridge University Press.

Carruthers, P. (2005) The case for massively modular models of mind. In: Contemporary debates in cognitive science, ed. R. Stainton, pp. 205-225. Oxford, England: Blackwell.

Carruthers, P. (2011) I do not exist. Trends in Cognitive Sciences 15(5):189-190.

Cattell, R. B. (1963). Theory of fluid and crystallized intelligence: A critical experiment. Journal of Educational Psychology, 54(1), 1-22.

Cattell, R. B. (1987) Intelligence: Its Structure, Growth and Action. New York: Elsevier.

Chang, Y. (2014) Reorganization and plastic changes of the human brain associated with skill learning and expertise. Frontiers in Human Neuroscience 8:35.

Chabris, C. F. (2007) Cognitive and neurobiological mechanisms of the law of general intelligence. In: Integrating the mind: Domain general versus domain specific processes in higher cognition, ed. M. J. Roberts, pp. 449-491. Hove, Uk: Psychology Press.

Chiappe, D. \& Gardner, R. A. (2012) The modularity debate in evolutionary psychology. Theory \& Psychology 22(5):669-682.

Chittka, L. \& Niven, J. (2009) Are bigger brains better? Current Biology 19(21):R995-R1008.

Chudasama, Y. (2011) Animal models of prefrontal-executive function. Behavioral Neuroscience 125(3):327-343.

Clune, J., Mouret, J. B., \& Lipson, H. (2013). The evolutionary origins of modularity. Proceedings of the Royal Society of London B: Biological Sciences, 280(1755), 20122863.

Colom, R., Abad, F. J., Rebollo, I. \& Shih, P. C. (2005) Memory span and general intelligence: A latent-variable approach. Intelligence 33:623-642. 
Colom, R., Jung, R. E. \& Haier, R. J. (2006) Distributed brain sites for the $g$-factor of intelligence. Neuroimage 31(3):1359-1365.

Coltheart, M. (2011) Methods for modular modelling: additive factors and cognitive neuropsychology. Cognitive Neuropsychology 28(3-4):224-240.

Cook, M. \& Mineka, S. (1989) Observational conditioning of fear to fear-relevant versus fear-irrelaevant stimuli in rhesus monkeys. Journal of Abnormal Psychology 98:448-459.

Cosmides, L. Barrett, H. C. \& Tooby, J. (2010) Adaptive specializations, social exchange, and the evolution of human intelligence. Proceedings of the National Academy of Sciences, 107(Supplement 2):9007-9014.

Cosmides, L. \& Tooby, J. (1994) Origins of domain specificity: The evolution of functional organization. In: Mapping the mind: Domain specificity in cognition and culture, ed. L. Hirschfeld \& S. Gelman. New York: Cambridge University Press, 85-116.

Cosmides, L. \& Tooby, J. (2002) Unraveling the enigma of human intelligence: Evolutionary psychology and the multimodular mind. In: The evolution of intelligence, eds. R. J. Sternberg \& J. C. Kaufman, Erlbaum:145-198.

Cosmides, L. \& Tooby, J. (2013) Evolutionary Psychology: New Perspectives on Cognition and Motivation. Annual Review of Psychology 64:201-229.

d'Souza, D. \& Karmiloff-Smith, A. (2011) When modularization fails to occur: A developmental perspective. Cognitive Neuropsychology 28(3-4):276-287.

Davis, G. et al. (2011) Genome-wide association studies establish that human intelligence is highly heritable and polygenic. Molecular Psychiatry 16, 996-1005.

Dahl, C. D., Chen, C. C., \& Rasch, M. J. (2014). Own-race and own-species advantages in face perception: a computational view. Scientific reports, 4.

Dean, L. G., Vale, G. L., Laland, K. N., Flynn, E. \& Kendal, R. L. (2014) Human cumulative culture: a comparative perspective. Biological Reviews 89(2):284-301.

Deaner, R.O., van Schaik C.P. \& Johnson V. E. (2006) Do some taxa have better domaingeneral cognition than others? A meta-analysis of nonhuman primate studies. Evolutionary Psychology 4:149-196.

Deaner, R. O., Isler, K., Burkart, J. M. \& van Schaik, C. P. (2007) Overall brain size, and not encephalization quotient, best predicts cognitive ability across non-human primates. Brain, Behaviour and Evolution 70(2):115-124.

Deary, I. J., Penke, L. \& Johnson, W. (2010) The neuroscience of human intelligence differences. Nature Reviews Neuroscience 11(3):201-211.

Diamond, A. (2013) Executive functions. Annual Review of Psychology 64:135.

Drake, J. M. (2007) Parental investment and fecundity, but not brain size, are associated with establishment success in introduced fishes. Functional Ecology 21(5):963-968.

Ducatez, S., Clavel, J. \& Lefebvre, L. (2015) Ecological generalism and behavioural innovation in birds: technical intelligence or the simple incorporation of new foods? Journal of Animal Ecology 84(1):79-89.

Duchaine, B., Cosmides, L. \& Tooby, J. (2001) Evolutionary psychology and the brain. Current Opinion in Neurobiology 11(2):225-230.

Dunbar, R. I. M. (1992) Neocortex size as a constraint on group size in primates. Journal of Human Evolution 20:469-493.

Dunbar, R. I. M. \& Shultz, S. (2007a) Evolution in the Social Brain. Science 317:1344-1347.

Dunbar, R. I. M. \& Shultz, S. (2007b) Understanding primate brain evolution. Philosophical Transactions of the Royal Society B: Biological Sciences 362(1480):649-658.

Embretson, S. E. (1995). The role of working memory capacity and general control processes in intelligence. Intelligence, 20(2), 169-189.

Eraña, A. (2012) Dual process theories versus massive modularity hypotheses. Philosophical Psychology 25(6):855-872.

Evans, J. S. B. (2011) Dual-process theories of reasoning: Contemporary issues and developmental applications. Developmental Review 31(2):86-102.

Evans, J. S. B. T. (2013). Two minds rationality. Thinking \& Reasoning, 20, 129-146. 
Fernandes, H. B. F., Woodley, M. A. \& te Nijenhuis, J. (2014) Differences in cognitive abilities among primates are concentrated on G: Phenotypic and phylogenetic comparisons with two meta-analytical databases. Intelligence 46:311-322.

Firestone, C., \& Scholl, B. J. (2015). Cognition does not affect perception: Evaluating the evidence for "top-down" effects. Behavioral and brain sciences, 1-72.

Fodor, J. A. (1983) Modularity of the Mind: The MIT Press.

Forss, S. I. F., Schuppli, C., Haiden, D., Zweifel, N. \& van Schaik, C. P. (2015) Contrasting responses to novelty by wild and captive orangutans. American Journal of Primatology 77(10):1109-1121.

Frankenhuis, W. E. \& Ploeger, A. (2007) Evolutionary psychology versus Fodor: Arguments for and against the massive modularity hypothesis. Philosophical Psychology 20(6):687710.

Galef, B. G. (2015). Laboratory studies of imitation/field studies of tradition: Towards a synthesis in animal social learning. Behavioural Processes, 112, 114-119.

Galsworthy, M. J., Arden, R. \& Chabris, C. F. (2014) Animal models of general cognitive ability for genetic research into cognitive functioning. In: Behavior genetics of cognition across the lifespan, eds. D. Finkel \& C. A. Reynolds, pp. 257-278. New York: Springer.

Galsworthy, M. J., Paya-Cano J. L., Monleo S. \& Plomin R. (2002) Evidence for general cognitive ability $(\mathrm{g})$ in heterogeneous stock mice and an analysis of potential confounds. Genes, Brain and Behavior 1:88-95.

Galsworthy, M. J, Paya-Cano, J. L., Liu, L., Monleón, S., Gregoryan, G., Fernandes, C., Schalkwyk, L. C. \& Plomin, R. (2005). Assessing reliability, heritability and general cognitive ability in a battery of cognitive tasks for laboratory mice. Behavioral Genetics 35(5):675-92.

Garcia, J. \& Koelling, R. A. (1966) Relation of cue to consequence in avoidance learning. Psychonomic Science 4(1):123-124.

Garson, D. G. (2013) Factor Analysis. Asheboro NC: Statistical Associates Publishing.

Geary, D. C. (1995). Reflections of evolution and culture in children's cognition: Implications for mathematical development and instruction. American Psychologist, 50(1), 24.

Geary, D. C. (2005) The origin of mind. Evolution of brain, cognition, and general Intelligence. Washington: American Psychological Association.

Geary, D. C. (2009) The evolution of general fluid intelligence. In: Foundations in Evolutionary Cognitive Neuroscience, eds S. M. Platek \& T. K. Shackelford. Cambridge: Cambridge University Press:22-56.

Geary, D. C., \& Huffman, K. J. (2002). Brain and cognitive evolution: forms of modularity and functions of mind. Psychological bulletin, 128(5), 667.

Gelman, R. (1990). First principles organize attention to and learning about relevant data: Number and the animate-inanimate distinction as examples. Cognitive science, 14(1), 79-106.

Gläscher, J., Rudrauf, D., Colom, R., Paul, L. K., Tranel, D., Damasio, H. \& Adolphs, R. (2010) Distributed neural system for general intelligence revealed by lesion mapping. Proceedings of the National Academy of Sciences 107(10):4705-4709.

Glickman, S. E., \& Sroges, R. W. (1966). Curiosity in zoo animals. Behaviour, 26(1), 151187.

Gottfredson, L. S. (1997) Mainstream science on intelligence: An editorial with 52 signatories, history, and bibliography. Intelligence 24(1):13-23.

Greenough, William T., James E. Black, and Christopher S. Wallace. Experience and brain development. Child development (1987): 539-559.

Grossi, G. (2014) A module is a module is a module: evolution of modularity in Evolutionary Psychology. Dialectical Anthropology 38(3):333-351.

Grossman, H. C., Hale, G., Light, K., Kolata, S., Townsend D. A, Goldfarb, Y., Kusnecov, A. \& Matzel, L. D. (2007) Pharmacological modulation of stress reactivity dissociates general learning ability from the propensity for exploration. Behavioral Neuroscience 121(5):949. 
Gruber, T., Muller, M. N., Reynolds, V., Wrangham, R. \& Zuberbühler, K. (2011)

Community-specific evaluation of tool affordances in wild chimpanzees. Scientific Reports 1:128.

Heldstab, S. A., Kosonen, Z. K., Koski, S. E. Burkart, J. M., van Schaik, C. P., \& Isler, K. Handy primates are clever primates. (2016.) Scientific Reports, 6.

Herndon, J. G., Moss, M. B., Rosene, D. L. \& Killiany, R. (1997) Patterns of cognitive decline in aged rhesus monkeys. Behavioural Brain Research 87:25-34.

Herrmann, E. \& Call, J. (2012) Are there geniuses among the apes? Philosophical Transactions of the Royal Society B 367:2753-2761.

Herrmann, E., Call, J., Hernandez-Lloreda, M. V., Hare, B. \& Tomasello, M. (2007) Humans have evolved specialized skills of social cognition: The Cultural Intelligence Hypothesis. Science 317:1360-1366.

Herrmann E., Hernandez-Lloreda, M. V., Call J., Hare B. \& Tomasello M. (2010a) The structure of individual differences in the cognitive abilities of children and chimpanzees. Psychological Science 21(1):102-110.

Herrmann, E., Hare, B., Call, J., \& Tomasello, M. (2010b). Differences in the cognitive skills of bonobos and chimpanzees. PLoS One, 5(8): e12438.

Heyes, C. M. (1994). Social learning in animals: categories and mechanisms. Biological Reviews, 69(2), 207-231.

Heyes, C. (2003) Four routes of cognitive evolution. Psychological Review 110(4):713-727.

Heyes, C. (2012) What's social about social learning? Journal of Comparative Psychology, 126(2):193-202.

Heyes, C. (2016). Who Knows? Metacognitive Social Learning Strategies. Trends in cognitive sciences.

Holekamp, K. E. (2007). Questioning the social intelligence hypothesis. Trends in Cognitive Sciences, 11(2), 65-69.

Holekamp, K. E., Dantzer, B., Stricker, G., Yoshida, K. C. S. \& Benson-Amram, S. (2015) Brains, brawn and sociality: a hyaena's tale. Animal Behaviour 103:237-248.

Hopkins, W. D., Russel, J. L. \& Schaeffer, J. (2014) Chimpanzee Intelligence is heritable. Current Biology 24:1649-1652.

Hoppitt, W., \& Laland, K. N. (2013). Social learning: an introduction to mechanisms, methods, and models. Princeton University Press.

Hrdy, S. (2009) Mothers \& Others: The Evolutionary Origins of Mutual Understanding. Cambridge: Harvard University Press.

Hufendiek, R. \& Wild, M. (2015) Faculties and Modularity. In: The Faculties: A History, ed. D. Perler, pp. 254-299. New York: Oxford University Press.

Humphrey, N. K. (1976) The social function of intellect. In: Growning Points in Ethology, eds. P. P. G. Bateson \& R. A. Hinde, 303-317. Cambridge: Cambridge University Press.

Husby, A., \& Husby, M. (2014) Interspecific analysis of vehicle avoidance behavior in birds. Behavioral Ecology 25(3):504-508.

Isler, K., \& van Schaik, C. P. (2014) How humans evolved large brains: Comparative evidence. Evolutionary Anthropology: Issues, News, and Reviews 23(2):65-75.

Jaeggi, A. V., Dunkel, L. P., Van Noordwijk, M. A., Wich, S. A., Sura, A. A. \& van Schaik, C. P. (2010) Social learning of diet and foraging skills by wild immature Bornean orangutans. American Journal of Primatology 72:62-71.

Jensen, A. R. \& Weng, L.-J. (1994) What is a good g? Intelligence 18(3):231-258.

Johansen-Berg, H. (2007) Structural plasticity: rewiring the brain. Current Biology 17(4):R141-R144.

Johnson, V. E., Deaner, R. O. \& van Schaik, C. P. (2002) Bayesian analysis of rank data with application to primate intelligence experiments. Journal of the American Statistical Association 97(457):8-17.

Jolly, A. (1966). Lemur social behaviour and primate intelligence. Science, 153(3735):501506. 
Joshi, P. K., Esko, T., Mattsson, H., Eklund, N., Gandin, I., Nutile, T., . . Zhang, W. (2015) Directional dominance on stature and cognition in diverse human populations. Nature, 523(7561):459-462.

Jung, R. E. \& Haier, R. J. (2007) The Parieto-Frontal Integration Theory (P-FIT) of intelligence: Converging neuroimaging evidence. Behavioral and Brain Sciences, 30(02):135-154.

Kaegy, J., Savard, J. F \& Borgia, G. (2011) Complex relationship between multiple measures of cognitive ability and male mating success in satin bowerbirds, Ptilonorhynchus violaceus. Animal Behaviour 81(5):1063-1070.

Kahneman, D. (2011) Thinking, fast and slow. London, England: Penguin Books.

Kan, K.-J., Kievit, R. A., Dolan, C. \& van der Maas, H. V. (2011). On the interpretation of the CHC factor Gc. Intelligence 39(5):292-302.

Kaufman, S. B., DeYoung, C. G., Reis, D. L., \& Gray, J. R. (2011). General intelligence predicts reasoning ability even for evolutionarily familiar content. Intelligence, 39, 311322.

Kendal, R. L., Hopper, L. M., Whiten, A., Brosnan, S. F., Lambeth, S. P., Schapiro, S. J. \& Hoppitt, W. (2015) Chimpanzees copy dominant and knowledgeable individuals: implications for cultural diversity. Evolution and Human Behavior, 36(1):65-72.

Kievit, R. A., Frankenhuis, W. E., Waldorp, L. J., \& Borsboom, D. (2013). Simpson's Paradox in psychological science: A practical guide. Frontiers in Psychology, 4, Article 513.

Kline, M. A. (2015). How to learn about teaching: An evolutionary framework for the study of teaching behavior in humans and other animals. Behavioral and Brain Sciences, 38, e31.

Klingberg, T. (2010) Training and plasticity of working memory. Trends in Cognitive Sciences, 14(7):317-324.

Koenig, A. (1998) Visual scanning by common marmosets (Callithrix jacchus): functional aspects and the special role of adult males. Primates 39:85-90.

Kolata, S., Light, K., Grossman, H. C., Hale, G. \& Matzel, L. D. (2007) Selective attention is a primary determinant of the relationship between working memory and general learning ability in outbred mice. Learning \& Memory 14(1-2):22-28.

Kolata, S., Light, K. \& Matzel, L. D. (2008). Domain-Specific and Domain-General Learning Factors are Expressed in Genetically Heterogeneous CD-1 mice. Intelligence 36(6):619629.

Kolata, S., Light K., Townsend, D. A., Hale, G., Grossman, H. C. \& Matzel, L. D. (2005) Variations in working memory capacity predict individual differences in general learning abilities among genetically diverse mice. Neurobiology of Learning and Memory 84:241246.

Kolata, S., Light, K., Wass, C. D., Colas-Zelin, D., Roy, D. \& Matzel, L. D. (2010) A dopaminergic gene cluster in the prefrontal cortex predicts performance indicative of general intelligence in genetically heterogeneous mice. PLoS One 5(11):e14036-e14036.

Kolodny, O., Edelman, S. \& Lotem, A. (2015) Evolved to adapt: A computational approach to animal innovation and creativity. Current Zoology 61:350-367.

Kolb, B., \& Gibb, R. (2015). Plasticity in the prefrontal cortex of adult rats. Frontiers in Cellular Neuroscience 9:15.

Koops K., Furuichi, T. \& Hashimoto, C. (2015) Chimpanzees and bonobos differ in intrinsic motivation for tool use. Scientific Reports 5:11356.

Korman, J., Voiklis, J. \& Malle, B. F. (2015) The social life of cognition. Cognition 135:3035.

Krakauer, E. B. (2005). Development of Aye-Aye (Daubentonia madagascariensis) foraging skills: Independent exploration and social learning. Duke University, Durham NC.

Kuzawa, C. W., Chugani, H. T., Grossman, L. I., Lipovich, L., Muzik, O., Hof, P. R., Wildman, D. E., Sherwood, C. C., Leonard W. R. \& Lange, N. (2014) Metabolic costs 
and evolutionary implications of human brain development. Proceedings of the National Academy of Sciences 111(36):13010-13015.

Lefebvre, L. (2013) Brains, innovations, tools and cultural transmission in birds, non-human primates, and fossil hominins. Frontiers in Human Neuroscience 7: 245.

Lefebvre, L. (2014) Should neuroecologists separate Tinbergen's four questions? Behavioural Processes 117:92-96.

Lefebvre, L., Reader, S. M. \& Sol, D. (2004) Brains, innovations and evolution in birds and primates. Brain, Behavior and Evolution 63:233-246.

Lefebvre, L., Reader, S. M. \& Sol, D. (2013) Innovating innovation rate and its relationship with brains, ecology and general intelligence. Brain, Behavior and Evolution 81(3):143145 .

Lefebvre, L., Whittle, P., Lascaris, E. \& Finkelstein, A. (1997) Feeding innovations and forebrain size in birds. Animal Behaviour 53:549-560.

Lesage, E., Navarrete, G. \& De Neys, W. (2013) Evolutionary modules and Bayesian facilitation: The role of general cognitive resources. Thinking \& Reasoning 19(1):27-53.

Light K. R., Grossman H., Kolata S., \& Matzel L. D. (2011) General learning ability regulates exploration through its influence on rate of habituation. Behavioural Brain Research 223(2):297-309.

Light K. R., Kolata S., Hale G., Grossman H., and Matzel L. D. (2008) Up-regulation of exploratory tendencies does not enhance general learning abilities in juvenile or youngadult outbred mice. Neurobiology of Learning and Memory 90:317-329.

Light K. R., Kolata S., Wass C., Denman-Brice A., Zagalsky R., and Matzel L. D. (2010) Working memory training promotes general cognitive abilities in genetically heterogeneous mice. Current Biology 20:777-782.

Locurto C. (1997) On the comparative generality of g. In: Advances in cognition and education, vol. 4: Reflections on the concept of intelligence, eds. W. Tomic \& J. Kigman, pp. 79-100. Greenwich, CT: JAI Press.

Locurto, C., Benoit, A., Crowley, C. \& Miele, A. R. (2006) The structure of individual differences in batteries of rapid acquisition tasks in mice. Journal of Comparative Psychology, 120:378-388.

Locurto, C., Fortin, E. \& Sullivan, R. (2003) The structure of individual differences in heterogeneous stock mice across problem types and motivational systems. Genes, Brain and Behavior 2(1):40-55.

Locurto, C. \& Scanlon, C. (1998) Individual differences and a spatial learning factor in two strains of mice (Mus musculus). Journal of Comparative Psychology 112(4):344-352.

Lotem, A. \& Halpern, J. Y. (2012) Coevolution of learning and data-acquisition mechanisms: a model for cognitive evolution. Philosophical Transactions of the Royal Society of London B: Biological Sciences 367(1603):2686-2694.

Luncz, L. V. \& Boesch, C. (2014) Tradition over trend: Neighboring chimpanzee communities maintain differences in cultural behavior despite frequent immigration of adult females. American Journal of Primatology 76(7):649-657.

MacLean, E. L., Hare, B., Nunn, C. L., Addessi, E., Amici, F., Anderson, R. C., . . Barnard, A. M. (2014) The evolution of self-control. Proceedings of the National Academy of Sciences, 111(20):E2140-E2148.

Macphail, E. M. (1982). Brain and intelligence in vertebrates. Oxford: Clarendon Press.

Mahon, B. Z. \& Cantlon, J. F. (2011) The specialization of function: Cognitive and neural perspectives. Cognitive Neuropsychology 28(3-4):147-155.

Major, J. T., Johnson, W. \& Deary, I. J. (2012) Comparing models of intelligence in Project TALENT: The VPR model fits better than the CHC and extended Gf-Gc models. Intelligence 40(6):543-559.

Matsunaga, E., Nambu, S., Oka, M., Tanaka, M., Taoka, M. \& Iriki, A. (2015) Identification of tool use acquisition-associated genes in the primate neocortex. Development, Growth \& Differentiation 57(6):484-495. 
Matzel, L. D., Grossman, H., Light, K., Townsend, D. \& Kolata, S. (2008) Age-related declines in general cognitive abilities of Balb/C mice are associated with disparities in working memory, body weight, and general activity. Learning \& Memory 15(10):733746.

Matzel, L. D., Han, Y. R., Grossmann, H., Karnik, M. S., Patel, D., Scott N., Specht, S. M. \& Gandhi C. C. (2003) Individual differences in the expression of a "general" learning ability in mice. The Journal of Neuroscience 23(16):6423-6433.

Matzel, L. D., Sauce, B., \& Wass, C. (2013) The architecture of intelligence. Converging evidence from studies of humans and animals. Current Directions in Psychological Science, 22(5), 342-348.

Matzel, L. D., Townsend, D. A., Grossman, H., Han, Y. R., Hale, G., Zappulla, M., Light, K. \& Kolata, S. (2006) Exploration in outbred mice covaries with general learning abilities irrespective of stress reactivity, emotionality, and physical attributes. Neurobiology of Learning and Memory 86:228-240.

Matzel, L. D., Wass, C. \& Kolata, S. (2011) Individual differences in animal intelligence: learning, reasoning, selective attention and inter-species conservation of a cognitive trait. International Journal of Comparative Psychology 24:36-59.

Matzel, L. D., Light, K. R., Wass, C., Colas-Zelin, D., Denman-Brice, A., Waddel, A. C. \& Kolata, S. (2011). Longitudinal attentional engagement rescues mice from age-related cognitive declines and cognitive inflexibility. Learning and Memory 18(5):345-356.

McGrew, K. S. (2009) CHC theory and the human cognitive abilities project: Standing on the shoulders of the giants of psychometric intelligence research. Intelligence 37(1):1-10.

Melnick, M. D., Harrison, B. R., Park, S., Bennetto, L., \& Tadin, D. (2013). A strong interactive link between sensory discriminations and intelligence. Current Biology, 23(11), 1013-1017.

Meulman, E. J. M., Sanz, C. M., Visalberghi, E. \& van Schaik, C. P. (2012) The role of terrestriality in promoting primate technology. Evolutionary Anthropology: Issues, News, and Reviews 21(2):58-68.

Meulman, E. J. M., Seed, A. M. \& Mann, J. (2013) If at first you don't succeed... Studies of ontogeny shed light on the cognitive demands of habitual tool use. Philosophical Transactions of the Royal Society of London B: Biological Sciences 368(1630):20130050.

Miyake, A., Friedman, N. P., Emerson, M. J., Witzki, A. H., Howerter, A., \& Wager, T. D. (2000). The unity and diversity of executive functions and their contributions to complex "frontal lobe" tasks: A latent variable analysis. Cognitive Psychology, 41(1), 49-100.

Moll, H., \& Tomasello, M. (2007). Cooperation and human cognition: the Vygotskian intelligence hypothesis. Philosophical Transactions of the Royal Society of London B: Biological Sciences, 362(1480), 639-648.

Morrison, A. B. \& Chein, J. M. (2011) Does working memory training work? The promise and challenges of enhancing cognition by training working memory. Psychonomic Bulletin \& Review 18(1):46-60.

Muthukrishna, M., \& Henrich, J. (2016). Innovation in the collective brain. Philosophical Transactions of the Royal Society B: Biological Sciences.

Nippak , P. M. \& Milgram, N. W. (2005) An investigation of the relationship between response latency across several cognitive tasks in the beagle dog. Prog Neuropsychopharmacol Biol Psychiatry 29(3):371-377.

Nisbett, R. E., Aronson, J., Blair, C., Dickens, W., Flynn, J., Halpern, D. F. \& Turkheimer, E. (2012) Intelligence: new findings and theoretical developments. American Psychologist, 67(2):130-159.

Ortiz, S. O. (2015) CHC Theory of Intelligence In: Handbook of Intelligence, ed. Goldstein et al. pp. 209-227. New York: Springer.

Parker, S. T. (2015) Re-evaluating the extractive foraging hypothesis. New Ideas in Psychology 37:1-12. 
Parker, S. T. \& Gibson, K. R. (1977) Object manipulation, tool use and sensomotor intelligence as feeding adaptations in cebus monkeys and great apes. Journal of Human Evolution 6:623-642.

Patton, B. W. \& Braithwaite, V. A. (2015) Changing tides: ecological and historical perspectives on fish cognition. Wiley Interdisciplinary Reviews: Cognitive Science 6(2):159-176.

Pavlicev, M. \& Wagner, G. P. (2012) Coming to grips with evolvability. Evolution: Education and Outreach 5(2):231-244.

Pietschnig, J., Penke, L., Wicherts, J.M., Zeiler, M., \& Voracek, M. (2015). Meta-analysis of associations between human brain volume and intelligence differences: How strong are they and what do they mean? Neuroscience and Biobehavioral Reviews, 57, 411-432.

Pinker, S. (2010). The cognitive niche: Coevolution of intelligence, sociality, and language. Proceedings of the National Academy of Sciences, 107(Supplement 2), 8993-8999.

Ploeger, A., \& Galis, F. (2011) Evo devo and cognitive science. Wiley Interdisciplinary Reviews: Cognitive Science 2(4):429-440.

Plomin, R. (2001) The genetics of $g$ in human and mouse. Nature Reviews Neuroscience 2(2): 136-141.

Pravosudov, V. V., \& Roth II, T. C. (2013). Cognitive ecology of food hoarding: the evolution of spatial memory and the hippocampus. Annual Review of Ecology, Evolution, and Systematics, 44, 173-193.

Prinz, J. J. (2006) Is the mind really modular? In: Contemporary Debates in Cognitive Science, ed. R. J. Stainton, pp. 22-36. Malden: Blackwell Publishing.

Quartz, S. (2003) Toward a developmental evolutionary psychology: Genes, development and the evolution of cognitive architecture. In: Evolutionary Psychology: Alternative Approaches, eds. S. J. Scher \& F. Rauscher, pp.185-210. Boston: Kluwer.

Rabipour, S. \& Raz, A. (2012) Training the brain: Fact and fad in cognitive and behavioral remediation. Brain and Cognition 79(2):159-179.

Reader, S. M. (2003) Innovation and social learning: individual variation and brain evolution. Animal Biology 53:147-158.

Reader, S. M., Hager, Y. \& Laland, K. N. (2011) The evolution of primate general and cultural intelligence. Philosophical Transactions of the Royal Society B: Biological Sciences, 366(1567):1017-1027.

Reader, S. M. \& Laland, K. N. (2002) Social intelligence, innovation and enhanced brain size in primates. Proceedings of the National Academy of Sciences of the USA 99:4436-4441.

Reeve, C. L. (2004) Differential ability antecedents of general and specific dimensions of declarative knowledge: More than $g$. Intelligence 32(6):621-652.

Reyes-García, V., Pyhälä, A., Díaz-Reviriego, I., Duda, R., Fernández-Llamazares, Á., Gallois, S., Guèze, M. and Napitupulu, L. (2016). Schooling, Local Knowledge and Working Memory: A Study among Three Contemporary Hunter-Gatherer Societies. PloS one, 11(1).

Richerson, P. J., Baldini, R., Bell, A., Demps, K., Frost, K., Hillis, V., Mathew, S., Newton, N. , Narr, N., Newson, L.; Ross, C., Smaldino, P., Waring, T. \& Zefferman, M. (2016) Cultural group selection plays an essential role in explaining human cooperation: A sketch of the evidence. Behavioral and Brain Sciences.

Riddell, W. I. \& Corl, K. G. (1977) Comparative investigation of the relationship between cerebral indices and learning abilities. Brain, Behavior and Evolution 14:385-398.

Royall, D. R. \& Palmer, R. F. (2014) "Executive functions" cannot be distinguished from general intelligence: two variations on a single theme within a symphony of latent variance. Frontiers in Behavioral Neuroscience 8(369):1-10.

Rumbaugh, D. M. \& Washburn, D. A. (2003) Intelligence of Apes and Other Rational Beings. New Haven: Yale University Press.

Saklofske, D. H., van de Vijver, F. J., Oakland, T., Mpofu, E., \& Suzuki, L. A. (2014). Intelligence and Culture: History and Assessment. Handbook of Intelligence: Evolutionary Theory, Historical Perspective, and Current Concepts, 341. 
Sale, A., Berardi, N. \& Maffei, L. (2014). Environment and brain plasticity: towards an endogenous pharmacotherapy. Physiological Reviews 94(1):189-234.

Samuels, R. (2004). Innateness in cognitive science. Trends in Cognitive Sciences, 8(3), 136141.

Sauce, B., Wass, C., Smith, A., Kwan, S. \& Matzel, L. D. (2014) The external-internal loop of interference: Two types of attention and their influence on the learning abilities of mice. Neurobiology of Learning and Memory 116:181-192.

Savage-Rumbaugh, S., Fields, W. M., Segerdahl, P. \& Rumbaugh, D. (2005) Culture prefigures cognition in Pan/Homo bonobos. Theoria. Revista de Teoría, Historia y Fundamentos de la Ciencia 20(3):311-328.

Schlosser, G. \& Wagner, G. P. (2004) Modularity in development and evolution. University of Chicago Press.

Schubiger, M. N., Wüstholz, F. L., Wunder, A. \& Burkart, J. M. (2015). High emotional reactivity toward an experimenter affects participation, but not performance, in cognitive tests with common marmosets (Callithrix jacchus). Animal Cognition 18(3):701-712.

Schuppli, C., Isler, K., \& van Schaik, C. P. (2012). How to explain the unusually late age at skill competence among humans. Journal of human evolution, 63(6), 843-850.

Schuppli, C., Meulman, E., Forss, S. F., van Noordwijk, M. \& van Schaik, C. P. (in rev.) Observational social learning and socially induced practice of routine skills in wild immature orang-utans.

Schubiger, M. N., Kissling, A., \& Burkart J. B. (in press). How task format affects cognitive performance: A memory test with two species of New World monkeys. Animal Behaviour.

Shah, P., Happé, F., Sowden, S., Cook, R., \& Bird, G. (2015). Orienting Toward Face-Like Stimuli in Early Childhood. Child Development, 86(6), 1693-1700.

Shaw, R. C., Boogert, N. J., Clayton, N. S. \& Burns, K. C. (2015) Wild psychometrics: evidence for 'general'cognitive performance in wild New Zealand robins, Petroica longipes. Animal Behaviour 109:101-111.

Sheppard, L. D., \& Vernon, P. A. (2008). Intelligence and speed of information-processing: A review of 50 years of research. Personality and Individual Differences, 44(3), 535-551.

Shepherd, S. V. (2010) Following gaze: gaze-following behavior as a window into social cognition. Frontiers in Integrative Neuroscience 4.

Sherry, D. F. (2006) Neuroecology. Annual Review of Psychology 57:167-197.

Shettleworth, S. J. (2012) Darwin, Tinbergen, and the evolution of comparative cognition. Oxford Handbook of Comparative Evolutionary Psychology, pp. 529-546.

Shettleworth, S. J. (2012) Modularity, comparative cognition and human uniqueness. Philosophical Transactions of the Royal Society B 367(1603):2794-2802.

Shipstead, Z., Redick, T. \& Engle, R. W. (2012) Is working memory training effective? Psychological Bulletin 138(4):628.

Shultz, S. \& Dunbar, R. I. M. (2006) Both social and ecological factors predict ungulate brain size. Proceedings of the Royal Society B: Biological Sciences 273(1583):207-215.

Shumway, C. A. (2008) Habitat complexity, brain, and behavior. Brain, Behavior and Evolution 72(2):123-134.

Sol, D. (2009) Revisiting the cognitive buffer hypothesis for the evolution of large brains. Biology Letters 5(1):130-133.

Sol, D., Bacher, S., Reader, S. M. \& Lefebvre, L. (2008) Brain size predicts the success of mammal species introduced into novel environments. The American Naturalist 172(S1):S63-S71.

Sol, D., Duncan, R. P., Blackburn, T. M., Cassey, P. \& Lefebvre, L. (2005) Big brains, enhanced cognition, and response of birds to novel enivronments. PNAS, 102(15):54605465 .

Spelke, E. S. \& Kinzler, K. D. (2007) Core knowledge. Developmental science, 10(1):89-96. Spearman C. (1927) The Abilities of Man. Oxford, England: Macmillan. xxii 415pp. 
Sperber, D. (2001) In defense of massive modularity. In: Language, Brain and Cognitive Devolopment: Essays in honor of Jacques Mehler, ed. E. Dupoux (Ed.), 47-57. Cambridge MA: MIT Press.

Sternberg, S. (2011) Modular processes in mind and brain. Cognitive Neuropsychology 28(34):156-208.

Stevens, J. P. (2012). Applied multivariate statistics for the social sciences. Routledge Tabachnick, B. \& Fidell, L. eds. (2007) Using Multivariate Statistics $5^{\text {th }}$ edition. Pearson Education.

Strasser, A., \& Burkart, J. M. (2012). Can we measure brain efficiency? An empirical test with common marmosets (Callithrix jacchus). Brain, Behavior and Evolution, 80(1), 2640.

Tapp, P. D., Siwak, C. T., Estrada, J., Head, E., Muggenburg, B. A., Cotman, C. W. \& Milgram, N. W. (2003) Size and reversal learning in the beagle dog as a measure of executive function and inhibitory control in aging. Learning \& Memory 10(1):64-73.

Teubert, M., Vierhaus, M. \& Lohaus, A. (2011) Frühkindliche Untersuchungsmethoden zur Intelligenzprognostik. Psychologische Rundschau, 62(2):70-77.

Thorsen, C., Gustafsson, J. E. \& Cliffordson, C. (2014) The influence of fluid and crystallized intelligence on the development of knowledge and skills. British Journal of Educational Psychology 84(4):556-570.

Tinbergen, N. (1963) On aims and methods of ethology. Zeitschrift für Tierpsychologie, 20(4): 410-433.

Toates, F. (2005) Evolutionary psychology-towards a more integrative model. Biology and Philosophy, 20(2-3):305-328.

Tomasello, M. (1999) The cultural origins of human cognition. Cambridge, MA: Harvard University Press.

Tomasello, M., \& Call, J. (1997) Primate Cognition. New York: Oxford University Press. van der Maas, H. L., Dolan, C. V., Grasman, R. P., Wicherts, J. M., Huizenga, H. M., \& Raijmakers, M. E. (2006). A dynamical model of general intelligence: The positive manifold of intelligence by mutualism. Psychological Review, 113, 842-861.

van de Waal, E., Borgeaud, C. \& Whiten, A. (2013). Potent social learning and conformity shape a wild primate's foraging decisions. Science 340(6131):483-485.

van Schaik, C. P. (2016) The primate origins of human nature. New York: Wiley-Blackwell.

van Schaik, C. P., Ancrenaz, M., Borgen, G., Galdikas, B., Knott, C. D., Singleton, I., Suzuki, A., Suci , S. U., \& Merrill, M. (2003). Orangutan cultures and the evolution of material culture. Science 299: 102-105.

van Schaik, C. P. \& Burkart, J. M. (2011) Social learning and evolution: the cultural intelligence hypothesis. Philosophical Transactions of the Royal Society B: Biological Sciences 366(1567).

van Schaik, C. P., Burkart, J. M., Damerius, L., Forss, S., Koops, K., van Noordwij, M. \& Schuppli, C. (2016). The reluctant innovator: Orangutans and the phylogeny of creativity. Philosophical Transactions of the Royal Society B, 371(1690), 20150183

van Schaik, C. P., Deaner, R. O. \& Merrill, M. Y. (1999) The conditions for tool use in primates: implications for the evolution of material culture. Journal of Human Evolution 36:719-741.

van Schaik, C. P., Graber, S. M., Schuppli, C. \& Burkart, J. M. (in rev.). The ecology of social learning in animals and its link with intelligence. Spanish Journal of Comparative Psychology.

van Schaik, C. P., Isler, K. \& Burkart, J. M. (2012) Explaining brain size variation: from social to cultural brain. Trends in Cognitive Sciences 16(5): 277-284.

van Woerden, J. T., van Schaik, C. P. \& Isler, K. (2014) Brief Communication: Seasonality of diet composition is related to brain size in New World Monkeys. American Journal of Physical Anthropology 154(4):628-632.

van Woerden, J. T., van Schaik, C. P. \& Isler, K. (2010) Effects of seasonality on brain size evolution: evidence from strepsirrhine primates. The American Naturalist 176(6):758767. 
van Woerden, J. T., Willems, E. P., van Schaik, C. P. \& Isler, K. (2012) Large brains buffer energetic effects of seasonal habitats in catarrhine primates. Evolution 66(1):191-199.

Voelk1, B., Schrauf, C. \& Huber, L. (2006) Social contact influences the response of infant marmosets towards novel food. Animal Behaviour 72:365-372.

Wass, C., Denman-Brice, A., Light, K. R., Kolata, S., Smith A. M. \& Matzel L. D. (2012) Covariation of learning and "reasoning" abilities in mice: evolutionary conservation of the operations of intelligence. Journal of Experimental Psychology: Animal Behavior Processes 38(2):109-124.

Whiten, A. \& van Schaik, C. P. (2007) The evolution of animal "cultures" and social intelligence. Philosophical Transactions of the Royal Society B: Biological Sciences 362(1480):603-620.

Woodley of Menie, M. A., Fernandes, H. B. F. \& Hopkins, W. D. (2015) The more g-loaded, the more heritable, evolvable, and phenotypically variable: Homology with humans in chimpanzee cognitive abilities. Intelligence 50:159-163.

Wooldridge, D. E. (1968) Mechanical man: The physical basis of intelligent life. McGrawHill Companies.

Yamamoto, M. E., Domeniconi, C. \& Box, H. (2004). Sex differences in common marmosets (Callithrix jacchus) in response to an unfamiliar food task. Primates 45:249-254.

Yoerg, S. I. (2001) Clever as a Fox. Animal Intelligence and what it can teach us about ourselves. New York: Bloomsbury. 